\title{
Modeling of the northern hemisphere ice sheets during the last glacial cycle and glaciological sensitivity
}

\author{
Chris Zweck and Philippe Huybrechts \\ Alfred-Wegener-Institut für Polar - und Meeresforschung, Bremerhaven, Germany \\ Received 5 October 2004; revised 7 February 2005; accepted 16 February 2005; published 7 April 2005.
}

[1] We present a new three-dimensional thermomechanically coupled ice sheet model of the northern hemisphere to reconstruct the Quaternary ice sheets during the last glacial cycle. The model includes basal sliding, internally calculated surface mass balance, glacial isostasy, and a treatment for marine calving. The time dependent forcing consists of temperature and precipitation anomalies from the United Kingdom Meteorological Office (UKMO) General Circulation Model scaled to the Greenland Ice Core Project (GRIP) ice core $\delta^{18} \mathrm{O}$ record. Model parameters were chosen to best match geomorphological inferences on Last Glacial Maximum extent and global eustatic sea level change. For our standard run we find a maximum ice volume of $57 \times 10^{6} \mathrm{~km}^{3}$ at $18.5 \mathrm{ka}$ cal BP. This corresponds to a eustatic sea level lowering of $110 \mathrm{~m}$ after correction for hydro-isostatic displacement and anomalous ice resulting from defects in the specified boundary conditions of the Paleoclimate Model Intercomparison Project (PMIP) for which the UKMO GCM results were generated. Of this $110 \mathrm{~m}, 82 \mathrm{~m}$ was stored in the North American ice sheet and $25 \mathrm{~m}$ in the Eurasian ice sheet. We determine the qualitative and quantitative response of the model from a comprehensive sensitivity study in which 11 important parameters were varied over their respective ranges of uncertainty. Model outputs comparable to the observational record were explored in detail as a linear function along the axes of parameter space of the reference model. The method reveals the dominance of climate uncertainty when modeling the Last Glacial Maximum configuration of the northern hemisphere ice sheets, but also highlights the role of ice rheology and basal processes for ice sheet thickness, and glacial isostasy and calving for the timing of maximum ice volume.

Citation: Zweck, C., and P. Huybrechts (2005), Modeling of the northern hemisphere ice sheets during the last glacial cycle and glaciological sensitivity, J. Geophys. Res., 110, D07103, doi:10.1029/2004JD005489.

\section{Introduction}

[2] One of the most prominent features of the Quaternary ice ages is the formation and decay of massive ice bodies on the continents of the northern hemisphere. Observational data increasingly well constrain the maximum extent of the ice sheets during the Last Glacial Maximum (LGM, 21000 years BP) [Clark and Mix, 2002] as well as the history of their subsequent retreat. Recent geomorphological work in northern Europe has significantly redefined the LGM extent of the Fennoscandian Ice Sheet in the Barents and Kara Seas [Svendsen et al., 2004a], opposing earlier reconstructions that had an Arctic ice sheet extending well beyond the Taimyr Peninsula into northern Siberia [Grosswald, 1993]. The previously controversial view that the Innuitian Ice Sheet covered most of northern Canada now appears to be generally accepted [Dyke et al., 2002], and so does the nature of its connec-

Copyright 2005 by the American Geophysical Union. 0148-0227/05/2004JD005489\$09.00 tion with the Greenland ice sheet [England, 1999]. There are little unresolved issues concerning the southern margin extent in North America and northern Europe, except for the possible connection between the Fennoscandian and British ice sheets, with most recent work arguing against their coalescence [Bowen et al., 2002]. Figure 1 shows a map of LGM extent according to many of these recent sources.

[3] However the thickness and volume of these ice sheets and their evolution over time are much harder to reconstruct from geomorphological evidence and generally need to be inferred from indirect evidence and modeling. The most direct measure of global ice volume are changes in global sea level. These can be inferred from drilling into tropical coral reefs [Fairbanks, 1989; Bard et al., 1996], but only a few of these records exist and debate continues on how to best correct for vertical land movements to extract the iceequivalent (eustatic) component of sea-level change. A more powerful constraint on the time-dependent change in global ice volume comes from glacio-isostatic modeling of observations of sea level change in regions far away from 


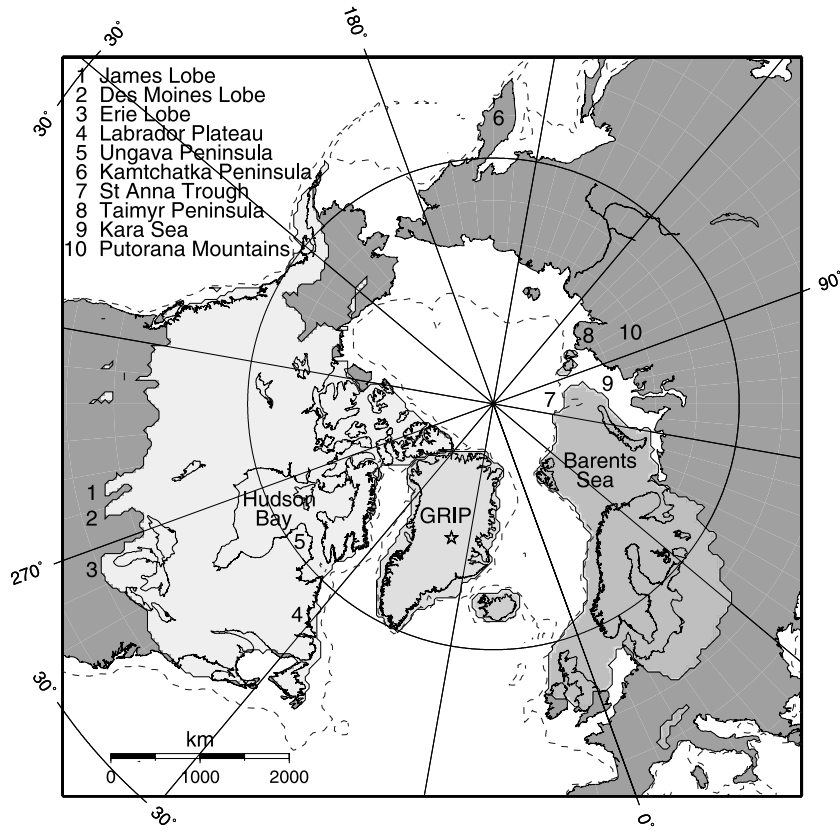

Figure 1. Location map and revised Last Glacial Maximum ice extent based on work from Svendsen et al. [1999] and Dyke and Prest [1987]. The map has been updated to include new data from Dyke et al. [2002] (revised Innuitian Ice Sheet extent) and Mangerud et al. [2002] (revised Kara Sea Ice Sheet extent). The three main ice sheet systems are plotted in different shades of gray (light $=$ North American ice sheet; medium $=$ Greenland and Iceland ice sheets; dark $=$ Eurasian ice sheet). The dashed line shows the location of the $500 \mathrm{~m}$ bathymetric depth of the ocean.

the ice sheets [Yokoyama et al., 2000; Peltier, 2002; Milne et al., 2002]. By accounting for glacio/hydro-isostatic adjustment and spatial variations in the geoid, these models predict time-dependent area-integrated ice volume changes over the surface of the Earth. From modeling the sea-level equation, these studies indicate that the total ice sheet volume change since the LGM has been between 115 and $135 \mathrm{~m}$ [Milne et al., 2002], a value well supported by geochemical records of oxygen isotopes from deep-sea sediment cores [Shackleton, 1987; Waelbroeck et al., 2002] and regarded as the uncertainty range by the EPILOG (Environmental Processes of the Ice Age: Land, Oceans, Glaciers) group [Clark and Mix, 2002]. A shortcoming of this result is that the source contributions from individual ice sheets are undetermined, although the pattern of global sea level change has recently been thought to be able to be attributable to volume changes from particular ice sheets because each would leave a distinct fingerprint [Clark et al., 2002]. A linked approach focuses on interpretation of records of relative sea-level change in the vicinity of the former ice sheets in terms of the local ice loading history [Peltier, 1994; Lambeck, 1995]. However, the problem appears also here underdetermined and a range of solutions exists depending on the specific set of rheological parameters (lithosphere thickness, mantle viscosity, etc) used in the glacial isostatic model.

[4] The avenue followed here to reconstruct the volume, evolution, and extent of the northern hemisphere ice sheets is direct modeling of their ice thickness distribution over time. Current 3-D ice-sheet models have improved significantly over the last decade and have been shown to be able to realistically reproduce many of the observed features of the present-day ice sheets of Greenland and Antarctica [e.g., Ritz et al., 1997, 2001; Huybrechts, 2002]. Application of these models to a northern hemisphere domain has, however, raised the question to what extent parameters and procedures tuned for the present-day ice sheets can be generalized to the palaeo-ice sheets on the American and Eurasian continents. For instance, Tarasov and Peltier [2000] conclude that when the Laurentide and the presentday Greenland ice sheets are modeled with the same version of Glen's flow law the results are glaciologically incompatible. Other important sources of uncertainty concern the representation of crucial processes and feedbacks which operate at the interfaces with the atmosphere, ocean, and the underlying earth.

[5] One challenge is to quantify the role of subglacial processes to generate fast flow and explain low-sloping ice-sheet profiles inferred from isostatic and geological evidence. Enhanced basal sliding or deformation of soft sediments are often invoked as important sources of uncertainty in modeling the northern hemisphere ice sheets and as potential mechanisms of instability [Clark, 1994; Marshall et al., 2000; Calov et al., 2002]. Related instability mechanisms which draw the ice-sheet margins down towards the end of a glacial cycle have been discussed in connection with isostatic adjustments to the time-varying ice loading [Oerlemans and van der Veen, 1984]. Large uncertainties are also associated with the modeling of marine and/or floating ice dynamics and the parameterizations that have been developed to deal with iceberg calving and grounding-line dynamics [Pfeffer et al., 1997; Marshall and Clarke, 1999; Zweck and Huybrechts, 2003].

[6] Another issue concerns the representation of meteorological conditions over the ice sheets as required to determine the surface mass balance. Time series from ice cores [Dansgaard et al., 1993; Alley et al., 1997] and other proxies provide evidence of first-order features but do not give an accurate picture of the patterns of precipitation and temperature change over the major ice sheets. It is well accepted that the northern hemisphere ice sheets strongly influenced the climate because of strong feedbacks associated with their albedo, their effect on the atmospheric circulation and moisture transport [Kageyama and Valdes, 2000], and the impact of meltwater production on the deep-water circulation of the oceans [Weaver et al., 1998]. The most realistic simulations of past precipitation and temperature patterns are therefore expected to come from the use of General Circulation Models (GCMs). A current drawback of using such models is that they can only be used to simulate short periods of time, inhibiting truly interactively coupled icesheet/climate simulations over a full glacial cycle. Another cause for concern is the considerable scatter among current GCMs when used to predict mass balances over the ice sheets. Pollard et al. [2000] examined climatic fields from 17 GCMs which participated in the Paleoclimate Model Intercomparison Project (PMIP), and found significant differences in summer-surface temperatures and 
precipitation rates, thought to be mainly caused by largescale climatic processes.

[7] The goal of this paper is to quantify the sources of uncertainty associated with modeling the northern hemisphere ice sheets of the last glacial cycle. We document the results of a 3-D model applied to the northern hemisphere continents, with particular focus on the values and sensitivities of model parameters which reproduce the observed ice volume change and extent. Missing in this analysis are model predicted eustatic sea level contributions from the Antarctic ice sheet, for which Huybrechts [2002] and Denton and Hughes [2002] suggest a value of between 14 and $18 \mathrm{~m}$ of the 115 to $135 \mathrm{~m}$ of total LGM eustatic sea level lowering, and another 5 to $6 \mathrm{~m}$ from smaller ice caps thought to have been located mainly in Patagonia and the Himalayas [Clark and Mix, 2002]. As main tool we use an improved version of the Huybrechts and T'siobbel [1997] ice-sheet model. This model considers thermomechanical coupling, and includes non-Hookean visco-elastic bedrock adjustment, mass balance components, and a treatment for marine calving [Zweck and Huybrechts, 2003].

[8] Sensitivity studies of ice sheet models focusing on single northern hemisphere ice sheets have been thoroughly investigated in recent years, for example by Marshall et al. [2002] using an ensemble analysis for the North American Ice Sheet and by Siegert et al. [2001] using different climate and sea level scenarios for the Fennoscandian Ice Sheet. Although these analyses do make similar conclusions about the need to modify present day precipitation patterns, they do not allow explicit comparison of model results with the global eustatic sea level change observations. Other studies which have considered a northern hemisphere domain [e.g., Charbit et al., 2002; Bintanja et al., 2002] have simulated only the last deglaciation or used different climate forcings resulting in generally different ice-sheet configurations. For example Charbit et al. [2002] use multiple climate time slices instead of a single LGM to present day anomaly while Bintanja et al. [2002] use a mass balance model in concert with a spatial temperature distribution function determined from a GCM simulation. Here we pay specific attention to the sensitivity of poorly constrained ice sheet model parameters in an attempt to examine how well the values of these parameters can be generalized for all major ice sheets of the northern hemisphere. Previous sensitivity investigations of models of the northern hemisphere ice sheets have assessed overall sensitivity from determining most probable values of parameters based on comparisons of ensembles of ice sheet model output with observational data [e.g., Marshall et al., 2002; Tarasov and Peltier, 2004] or by examining the role of changes to specific components of the model such as the method of climate forcing interpolation, initial ice sheet configuration, basal processes and accumulation changes [e.g., Charbit et al., 2002], or the magnitude and seasonal amplitude in temperature forcing [e.g., Bintanja et al., 2002]. Our approach differs from these studies in that we take a more systematic approach and try to quantitatively establish a hierarchy of most sensitive model parameters. An advantage of this method is that by essentially scaling relevant ice sheet model output to the model parameters the dominant glaciological processes are highlighted without reference to the observational database, which is continually subject to addition and reinterpretation (for example the revision of LGM ice extent over the Kara Sea [Mangerud et al., 2002] or the recent ICE-5G revision of the spatial distribution of ice sheet thicknesses recovered through glacioisostatic modeling [Peltier, 2004]).

[9] This work is presented in four major sections. First, the relevant physics of the northern hemisphere ice sheet model is described. Second, the details of a 'reference' model run is outlined, the output of which is mostly consistent with global eustatic sea level and geomorphological observations. In the third section, this reference model is used to investigate the degree to which changes to the ice sheet model parameters affect changes in the behavior of the overall dynamics of the model. In the last section we attempt to quantify the effect of changes to each model parameter so that a hierarchy of important parameters in the ice sheet model can be established.

\section{Model Formulation}

\subsection{Ice Dynamic Model}

[10] In this work a further development of the northern hemisphere ice sheet model of Huybrechts and T'siobbel [1997] is used. The model is originally based on an Antarctic ice sheet model developed by Huybrechts [1990] and is quite similar in many aspects to other largescale three-dimensional thermo-mechanically coupled icesheet models developed since [e.g., Ritz et al., 1997; Tarasov and Peltier, 1999; Marshall et al., 2000]. In this model, only grounded ice is considered, with the force balance and thermodynamics simplified according to the zeroth-order shallow ice approximation as appropriate for large ice masses. There is no explicit treatment of iceshelf flow, but marine ice dynamics is included with a parameterization for marine calving that allows to determine the extent of ice grounded below sea level. The icesheet model has 17 layers in the vertical and a horizontal mesh size of $50 \mathrm{~km}$. With a model domain covering all of the northern hemisphere where widespread continental glaciation is thought to have taken place (with the exception of Tibet and the Himalayas), this corresponds to a Cartesian grid of $193 \times 193$ grid cells. Area calculations take into account the distortions caused by the map projection.

[11] Mass conservation is observed in the model through a continuity equation for ice thickness:

$$
\frac{\partial H}{\partial t}=-\nabla \cdot(\overline{\vec{v}} H)+M
$$

which states that local ice thickness changes arise from a balance between the horizontal divergence of the depthaveraged mass flux and the local mass balance at the upper and lower surfaces. The surface mass balance is defined as the local mean annual difference between snow accumulation and meltwater runoff. The ice velocity has a component from internal deformation and from basal sliding, both of which are a function of the ice temperature. A list of variables and parameters appearing in the various formulations is provided in Table 1 . 
Table 1. Variables and Constants Used in the Reference Model ${ }^{\mathrm{a}}$

\begin{tabular}{|c|c|c|c|}
\hline Symbol & Description & Value & Units \\
\hline$A_{s}$ & Sliding Parameter & $1.8 \times 10^{-11} \S$ & $\mathrm{N}^{-3} \mathrm{a}^{-1} \mathrm{~m}^{8}$ \\
\hline$A\left(T^{*}\right)$ & Flow rate factor & equation (6) & $\mathrm{Pa}^{-3} \mathrm{a}^{-1}$ \\
\hline$a$ & Arrhenius constant & $\begin{array}{l}1.14 \times 10^{-3} \text { if } T^{*}<263.15 \mathrm{~K} \\
5.47 \times 10^{12} \text { if } T^{*}>263.15 \mathrm{~K}\end{array}$ & $\mathrm{~Pa}^{-3} \mathrm{a}^{-1}$ \\
\hline$c_{m}$ & Rock heat capacity & 1000 & $\mathrm{~J} \mathrm{~kg}^{-1} \mathrm{~K}^{-1}$ \\
\hline$c_{p}$ & Specific heat capacity of ice & $2115+7.79293\left(T_{i}-273.15\right)$ & $\mathrm{J} \mathrm{kg}^{-1} \mathrm{~K}^{-1}$ \\
\hline$\stackrel{p}{D}$ & Flexural rigidity of the Earth & $10^{25} \S$ & $\mathrm{N} \mathrm{m}$ \\
\hline$E P P D$ & Expected amount of positive degree days & equation (9) & $\mathrm{d}^{\circ} \mathrm{C}$ \\
\hline$g$ & Acceleration due to gravity & 9.81 & $\mathrm{~m} \mathrm{~s}^{-2}$ \\
\hline$h$ & Bedrock elevation & & $\mathrm{m}$ \\
\hline$h_{0}$ & Isostatically unloaded surface elevation of the Earth & & $\mathrm{m}$ \\
\hline$H$ & Ice thickness & & $\mathrm{m}$ \\
\hline$H^{\text {sur }}$ & Surface elevation & $\max ($ subgrid $\max (h), H+h)$ & $\mathrm{m}$ \\
\hline$H_{c}$ & Bathymetric depth of marine ice limit & equation (12) & $\mathrm{m}$ \\
\hline$\Delta H_{s l}$ & Eustatic sea level stand relative to present day & & $\mathrm{m}$ \\
\hline$k_{i}$ & Thermal conductivity of ice & $3.101 \times 10^{8} \times \exp \left(-0.0057 T_{i}\right)$ & $\mathrm{J} \mathrm{m}^{-1} \mathrm{~K}^{-1} \mathrm{a}^{-1}$ \\
\hline$k_{m}$ & Thermal conductivity of bedrock & $1.041 \times 10^{8}$ & $\mathrm{~J} \mathrm{~m}^{-1} \mathrm{~K}^{-1} \mathrm{a}^{-1}$ \\
\hline$M$ & Mass balance & & $\mathrm{m} \mathrm{a}^{-1}$ \\
\hline$m_{r}$ & Normalized rate factor & $1 \S$ & - \\
\hline$n$ & Glacial index exponent & $1 \S$ & - \\
\hline$P D D F S$ & Positive Degree Day Factors & 3.0 (snow) $\S$ & $\mathrm{mm} \mathrm{d}^{-1}{ }^{\circ} \mathrm{C}^{-1}$ \\
\hline & & 8.0 (ice) $\S$ & water equation \\
\hline$P$ & Monthly surface precipitation & equation (14) & $\mathrm{mm} \mathrm{month}^{-1}$ \\
\hline$P_{U K M O}$ & Monthly precipitation output from UKMO GCM & & mm month ${ }^{-1}$ \\
\hline$P_{\text {Jaeger }}$ & Monthly precipitation observations from Jaeger & & $\mathrm{mm}$ month $^{-1}$ \\
\hline$P_{r}$ & Precipitation ratio rescaling factor between LGM and PD & $1 \S$ & - \\
\hline$Q$ & Activation energy for creep & $\begin{array}{l}60 \text { if } T^{*} \leq 263.15 \mathrm{~K} \\
139 \text { if } T^{*}>263.15 \mathrm{~K}\end{array}$ & $\mathrm{~kJ} \mathrm{~mol}^{-1}$ \\
\hline$R$ & Universal gas constant & 8.314 & $\mathrm{~J} \mathrm{~mol}^{-1} \mathrm{~K}^{-1}$ \\
\hline$T_{U K M O}^{s l}$ & Monthly sea level temperature output from UKMO GCM & & ${ }^{\circ} \mathrm{C}$ \\
\hline$T_{N C E P}^{S l}$ & Monthly sea level temperature observations from NCEP & & ${ }^{\circ} \mathrm{C}$ \\
\hline$T_{m o n}^{\text {sur }}$ & Monthly surface atmospheric temperature & equation (13) & ${ }^{\circ} \mathrm{C}$ \\
\hline$T_{m}$ & Bedrock temperature & & ${ }^{\circ} \mathrm{C}$ \\
\hline$T_{m e l t}$ & Pressure melting point of ice & $273.15-8.7 \times 10^{-4} H$ & $\mathrm{~K}$ \\
\hline$T_{r}$ & Temperature difference rescaling factor between LGM and PD & $1 \S$ & - \\
\hline$T_{i}$ & Ice temperature & & $\mathrm{K}$ \\
\hline$T^{*}$ & Ice temperature corrected for pressure melting point & $T^{*}=T_{i}-8.7 \times 10^{-4}(H+h-z)$ & $\mathrm{K}$ \\
\hline$t$ & Time & & a \\
\hline$w$ & Isostatic deflection of the Earth & & $\mathrm{m}$ \\
\hline$z$ & Vertical coordinate & & $\mathrm{m}$ \\
\hline$\beta(t)$ & Time dependent glacial index & & - \\
\hline$\gamma$ & Geothermal heat flux & $42 \S$ & $\mathrm{mW} \mathrm{m}{ }^{-2}$ \\
\hline$\gamma_{l}$ & Atmospheric lapse rate & -0.008 & $\mathrm{~K} \mathrm{~m}^{-1}$ \\
\hline$\nu$ & Ice velocity & & $\mathrm{m} \mathrm{a}^{-1}$ \\
\hline$\rho_{i}$ & Density of ice & 910 & $\mathrm{~kg} \mathrm{~m}^{-3}$ \\
\hline$\rho_{m}$ & Density of the Earth's mantle & 3300 & $\mathrm{~kg} \mathrm{~m}^{-3}$ \\
\hline$\rho_{w}$ & Density of sea water & 1028 & $\mathrm{~kg} \mathrm{~m}^{-3}$ \\
\hline$\sigma$ & Monthly mean surface temperature standard deviation & $5 \S$ & ${ }^{\circ} \mathrm{C}$ \\
\hline$\tau$ & Asthenospheric decay timescale & $3000 \S$ & $\mathrm{a}$ \\
\hline$\vec{\tau}$ & Shear stress & & $\mathrm{N} \mathrm{m}^{-2}$ \\
\hline$\phi$ & Internal frictional heating caused by ice deformation & & $\mathrm{J} \mathrm{m}^{-3} \mathrm{a}^{-1}$ \\
\hline
\end{tabular}

${ }^{\mathrm{a}} \mathrm{A}$ section mark in the third column denotes a parameter subject to the sensitivity tests. A dash in the last column denotes a dimensionless parameter.

[12] The temperature distribution throughout the ice sheet is computed from a prognostic equation stating conservation of heat:

$$
\frac{\partial T_{i}}{\partial t}=\frac{1}{\rho_{i}} \frac{\partial}{\partial z}\left(\frac{k_{i}}{c_{p}} \frac{\partial T_{i}}{\partial z}\right)-\vec{v} \cdot \nabla T_{i}+\frac{\phi}{\rho_{i} c_{p}}
$$

in which heat transfer is considered to result from vertical diffusion (first term), three-dimensional advection (second term), and internal frictional heating caused by ice deformation (last term). Thermal parameters are temperaturedependent as listed in Table 1. Horizontal heat diffusion is neglected commensurate with the usual simplifications of the shallow ice approximation which are made in large-scale ice-sheet models. Boundary conditions for the temperature of the ice sheet are that at the ice surface the temperature is equal to the annual mean air temperature. At the base of the ice sheet a heat flux is applied which depends on the timedependent heat conduction in an underlying rock slab of $4 \mathrm{~km}$ thickness, subject to a spatially uniform geothermal heat flux, and basal sliding at the ice-rock interface:

$$
\begin{gathered}
\left.\frac{\partial T_{i}}{\partial z}\right|_{h}=\frac{\gamma}{k_{i}}+\frac{\vec{\tau}(h) \vec{v}(h)}{k_{i}}=\frac{k_{m}}{k_{i}} \frac{\partial T_{m}}{\partial z}+\frac{\vec{\tau}(h) \vec{\nu}(h)}{k_{i}} \text { if } T_{i}<T_{\text {melt }} \\
T_{i}=T_{m e l t}=T_{m} \text { if } T_{i} \geq T_{\text {melt }} \\
\frac{\partial T_{m}}{\partial t}=\frac{k_{m}}{\rho_{m} c_{m}} \frac{\partial^{2} T_{m}}{\partial z^{2}}
\end{gathered}
$$


[13] In the standard run, the basal geothermal heat flux is set at $42 \mathrm{~mW} \mathrm{~m}^{-2}$, a typical value used for the geothermal heat flux emanating from Precambrian shields [Sclater et al., 1980], but this value is known to be spatially variable. Estimates for North America range from less than a third in the east to almost double the standard value in the tectonically active west [Blackwell and Steele, 1992].

[14] The temperature throughout the ice sheet is used to calculate the factor controlling the rate of the deformational flow of ice, which obeys an Arrhenius relation:

$$
A\left(T^{*}\right)=m_{r} a e^{\frac{-Q}{R T^{*}}}
$$

where the ice temperature $T^{*}$ is corrected for the dependence of the melting point on the pressure of the overlying ice. The flow rescaling (enhancement) factor used here is set at 20 times that used for modeling the Greenland ice sheet [Huybrechts, 2002], and is one-third lower than that used by Huybrechts and T'siobbel [1997]. Both the Arrhenius constant and the activation energy for creep in equation (6) are considered to be temperature dependent according to the relations provided in Table 1. As the work presented here focuses on sensitivity, for clarity $m_{r}$ is set to unity for the reference run by absorbing the enhancement factor of 100 in the values of $a$ given by Huybrechts [1990].

[15] The calculation of the flow rate factor allows computation of the deformational component of the horizontal ice velocity. Using Glen's flow law for polycrystalline ice with exponent 3 , and ignoring longitudinal and transverse strain rate components, this gives:

$$
\begin{gathered}
\vec{\nu}(z)-\vec{\nu}(h)=-2\left(\rho_{i} g\right)^{3}[\nabla(H+h) \cdot \nabla(H+h)] \nabla(H+h) \\
\cdot \int_{h}^{z} A\left(T^{*}\right)(H+h-z)^{3} d z
\end{gathered}
$$

[16] When the base of the ice sheet is at the pressure melting point, the presence of water is considered a sufficient condition to induce basal sliding. A physically realistic formulation of the processes governing basal motion has proven hard to establish. Most formulations employ a parameterization based on basal shear stress. Here we calculate the velocity at the base with a Weertman-type sliding law [Weertman, 1964] which relates basal sliding to basal shear stress raised to the third power:

$$
\vec{\nu}(h)=-A_{s}\left(\rho_{i} g H\right)^{3}[\nabla(H+h) \cdot \nabla(H+h)] \nabla(H+h)
$$

where $A_{s}$ is an empirical correlation coefficient considered to be physically analogous to the smoothness of the surface of the Earth over which the ice slides. Enhanced basal flow may also occur as a result of water-saturated basal sediment deformation [Fisher et al., 1985; Licciardi et al., 1998]. However, here we consider basal motion to result only from sliding, and do not attempt to deal with such issues such as basal hydraulics or till rheology. Given the uncertainty regarding the physics of basal motion we believe that model sensitivity can be reasonably examined by varying the basal flow parameter over an appropriate range.

[17] Given the velocity at the base of the ice sheet (equation (8)), the total horizontal velocity throughout the ice sheet is given by integration with height of the deformational velocity as computed by equation (7). The vertical velocity is determined by assuming ice incompressibility. The mass flux is then computed and used to determine changes in ice thickness using equation (1).

\subsection{Mass Balance Model}

[18] An important boundary condition for the ice sheet model is the annual surface mass balance. The mass balance model distinguishes between snow accumulation and ablation (meltwater runoff). The total amount of snowfall (accumulation) has a linear dependence on mean monthly surface temperature, bounded so that when surface temperature is less than $-10^{\circ} \mathrm{C}$ mean accumulation is equal to precipitation, and when surface temperature is greater than $7^{\circ} \mathrm{C}$, snow accumulation is zero and all precipitation occurs as rain. Surface melting and subsequent runoff, which depends on the details of the energy fluxes at the iceatmosphere interface, is better determined locally than is possible on the coarse grid of a climate model. Therefore, following what has become standard practice in large-scale ice-sheet models, the melting rate is set proportional to the yearly sum of positive degree days at the surface. Following a parameterization suggested by Janssens and Huybrechts [2000], the expected sum of positive degree days (EPPD) is evaluated as:

$$
\begin{aligned}
E P D D= & \sigma \int_{0}^{12} 30.4\left[0.3989 \exp \left(-1.58\left|\frac{T_{\text {mon }}^{\text {sur }}}{\sigma}\right|^{1.1372}\right)\right. \\
& \left.+\max \left(0, \frac{T_{\text {mon }}^{\text {sur }}}{\sigma}\right)\right] d t
\end{aligned}
$$

where the standard deviation is for temperature with respect to the monthly mean to account for the daily cycle and random weather fluctuations. The expected number of positive degree days is used to melt snow and ice. Our standard choice of degree-day factors of $3.0 / 8.0 \mathrm{~mm} \mathrm{~d}^{-1}$ ${ }^{\circ} \mathrm{C}^{-1}$ (water equivalent) are in the middle of the range suggested by Braithwaite [1995] from observations in central west Greenland. These coefficients are slightly higher than the values listed in ice equivalent by Huybrechts and T'siobbel [1997], because we have introduced a simple meltwater retention scheme. Based on similarities with results using significantly more complex meltwater refreezing and capillary water models of the Greenland ice sheet [Janssens and Huybrechts, 2000], here we specify that 30\% of the melted annual snowfall refreezes before runoff occurs. The fraction of rain is not accounted for in the retention process, and is assumed to run off entirely. The inputs to the mass balance model are mean monthly surface temperature and mean monthly precipitation rate over the entire grid.

\subsection{Isostatic Model}

[19] The glacial isostatic model consists of an elastic plate (lithosphere) that overlies a viscous asthenosphere. This approach has been shown to reproduce many of the features of the Earth's deformation resulting from the growth and decay of ice sheets as evident from more sophisticated visco-elastic treatments [Le Meur and Huybrechts, 1996]. The deflection of the Earth caused by the weight of ice 
sheets and oceans is determined by the rigidity of the lithosphere and the buoyancy of the mantle:

$$
D \nabla^{4} w+\rho_{m} g w= \begin{cases}\rho_{i} g H & \text { ice } \\ \rho_{w} g\left(\Delta H_{s l}-h\right) & \text { water }\end{cases}
$$

[20] The flexural rigidity parameter depends on the effective elastic thickness of the lithosphere, which according to thin plate theory [e.g., Cathles, 1975] corresponds to $105 \mathrm{~km}$ for its reference value given in Table 1 . The steady state deflection of the surface of the Earth is used to calculate the degree to which the Earth is in isostatic equilibrium, which is asymptotically attained using a relaxation formulation schematically representing the Earth's mantle:

$$
\frac{\partial h}{\partial t}=\frac{-\left(h-h_{0}-w\right)}{\tau}
$$

where the unloaded surface elevation of the Earth has been determined by assuming that the Earth is in present day isostatic equilibrium with both the ice and water loading. Lithosphere deflection is calculated in a square with sides of $1000 \mathrm{~km}$ to fully account for all loading contributions. Ocean areas at the margin of the numerical grid are therefore extended for this distance perpendicular to the edge to avoid boundary problems for a varying water load, the latter of which is assumed to follow a spatially uniform sea level elevation.

\subsection{Marine Extent Parameterization}

[21] Unlike the Antarctic ice sheet model of Huybrechts [1990], the northern hemisphere ice sheet model does not explicitly include ice shelf physics. Given the uncertainty regarding the existence and nature of ice shelves in the northern hemisphere during the last glacial cycle [Polyak et al., 2001], and the difficulties of implementing ice-shelf and grounding-line dynamics over a non-continuous domain, we use a simple parameterization which was validated to generate geomorphologically inferred changes in marine extent since the LGM. Main characteristics of these changes are the infiltration of the Barents Sea (Figure 1), thought to have occurred between 15 and $14 \mathrm{ka}$ cal BP [Svendsen et al., 2004b], and the infiltration of Hudson Bay at between 10 and 9 ka cal BP [Dyke et al., 2002], where both of these dates have been converted from radiocarbon to calendar years using the INTCAL98 timescale [Stuiver et al., 1998]. In the marine extent parameterization, grounded ice is considered to be able to flow beyond the present-day coastline and over the continental shelves until it reaches a critical water depth at which it calves completely. Usually considered to be constant [e.g., Tarasov and Peltier, 1999; Forsström and Greve, 2004], here the value of this bathymetric depth is considered to be a function of eustatic sea level, and therefore also of time. The equation relating the bathymetric depth of the marine limit to eustatic sea level change is

$$
H_{c}= \begin{cases}2.5 \Delta H_{s l} & \Delta H_{s l} \geq-80 \mathrm{~m} \\ 10.25\left(\Delta H_{s l}+80\right)-200 & \Delta H_{s l}<-80 \mathrm{~m}\end{cases}
$$

where $H_{c}$ is the depth of marine bathymetry to which the ice sheet is limited and $\Delta H_{s l}$ is the eustatic sea level change,


Figure 2. Time-dependent forcing used in the ice sheet model. The glacial index forcing is derived from combined Greenland Ice Core Project/Vostok data [Huybrechts, 2002]. The sea-level forcing is derived from the spectral mapping group (SPECMAP) at Brown University [Imbrie et al., 1984] data with modifications for the period $21 \mathrm{ka}$ cal BP to present day from Lambeck and Chappell [2001].

both measured relative to present sea level height. $H_{c}$ is taken as the contemporaneous marine bathymetry, which changes with time due to hydro-isostatic loading from eustatic sea-level change and glacio-isostatic loading from the advance and retreat of ice sheets. The calculation of water depth, however, does not include changes in absolute sea level (eustatic minus basin uplift) as these were found to have a second order effect compared to equation (12), which is already a function of sea level. The marine extent relationship is a hybrid equation (separated at $\Delta H_{s l}=-80 \mathrm{~m}$ ) with different gradients for different segments of eustatic sea level change. This was found to be required to correctly produce the timing for deglaciation of the major ice sheets and may be, amongst other things, climate related, as lower sea levels correspond to colder climates that allowed ice sheets to advance in deeper waters. Full details of the formulation and reasoning for equation (12) are given in Zweck and Huybrechts [2003]. The choice of coefficients for the parameterization, however, have changed slightly from that study because of some retuning to realistically reproduce the retreat of the Barents Sea and Hudson Bay for other parameter value changes.

[22] The eustatic sea level forcing $\Delta H_{s l}$ to drive our parameterization is based on data from the spectral mapping group (SPECMAP) at Brown University [Imbrie et al., 1984], but with modifications from Lambeck and Chappell [2001] so that the minimum in eustatic sea level occurs at $21 \mathrm{ka} \mathrm{cal} \mathrm{BP}$ and not at $18 \mathrm{ka}$ cal BP (as is the case in the SPECMAP record). This modified eustatic sea level record is shown as a function of time in Figure 2.

\subsection{Climate Forcing}

[23] The temporal and spatial characteristics of the climate forcing critically determine the input to the mass 

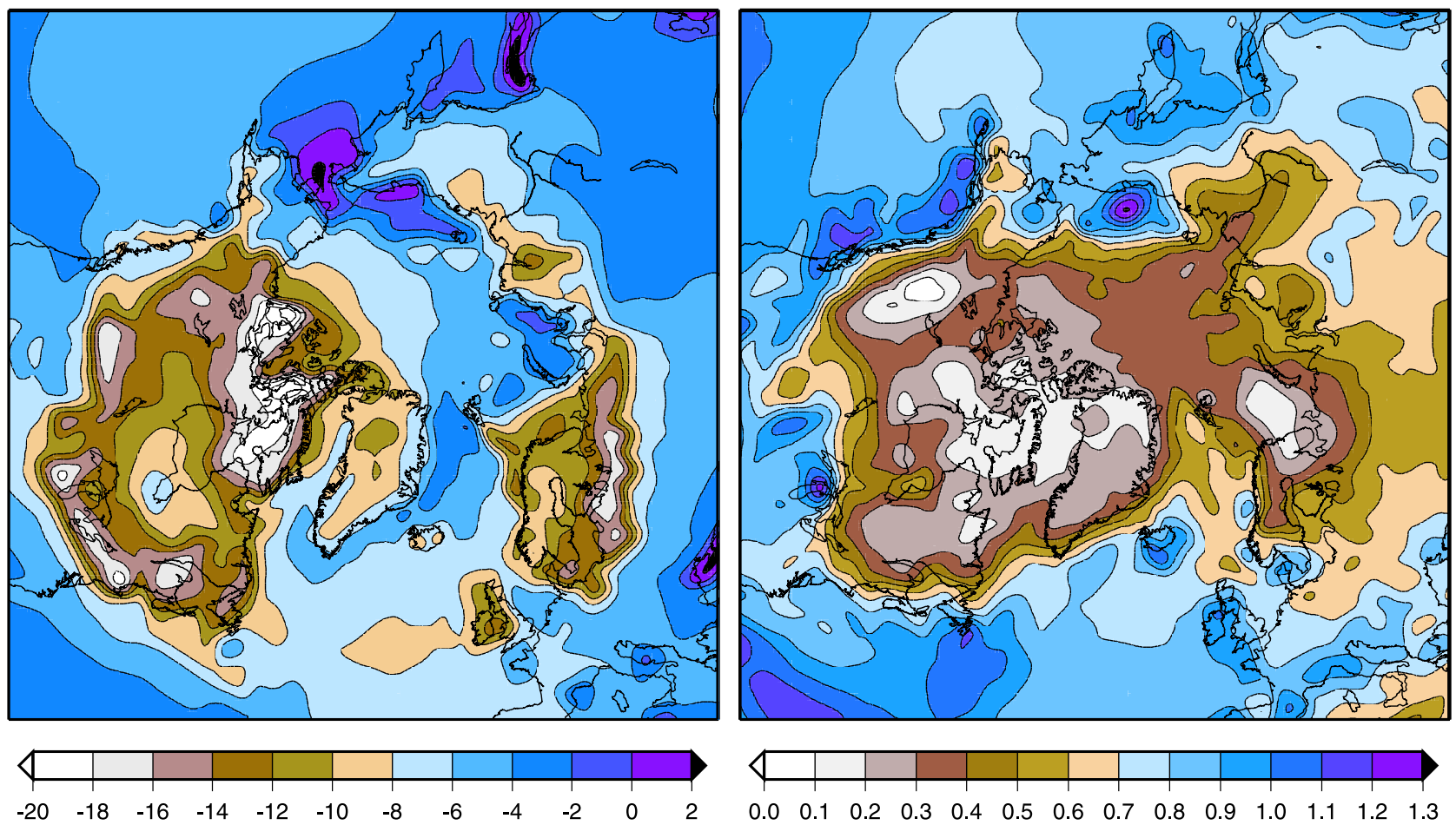

Figure 3. Summer mean temperature difference $\left({ }^{\circ} \mathrm{C}\right.$, left) and annual mean precipitation ratio (right) from United Kingdom Meteorological Office Paleoclimate Model Intercomparison Project (PMIP) time slice simulations presented as anomalies between the Last Glacial Maximum and the present day.

balance model. Our approach is similar to the perturbation ('delta') method applied in Huybrechts and T'siobbel [1997], except that the anomaly fields are taken from a fully-fledged GCM instead of from a rather coarse climate model of intermediate complexity, and that a procedure is developed to produce climatic forcing fields over a full glacial cycle. In this work the climatic perturbations are generated from the United Kingdom Meteorological Office (UKMO) GCM [Hewitt and Mitchell, 1997]. This model is version HADAM2b for the atmospheric component and is coupled to a mixed layer ocean model and a sea ice model, all at horizontal grid-resolution of 2.5 by 3.75 . HADAM2b has 19 levels in the vertical. A slightly different version of the model with some modifications in the atmospheric component participated in the PMIP exercises [Joussaume and Taylor, 1995]. In their analysis of mass balance estimates, Pollard et al. [2000] show that the UKMO GCM output compares reasonably well with the group mean of all models used in PMIP, and therefore this model represents a reasonable choice.

[24] From the GCM we use precipitation and sea-level temperature from time slice simulations of both the LGM and present day (PD). The LGM is taken at $21 \mathrm{ka}$ cal BP. It was obtained by prescribing the appropriate orbital parameters that control insolation at the top of the atmosphere, lowering the atmospheric $\mathrm{CO}_{2}$ concentration to glacial levels, and introducing the ICE-4G ice-sheet topography from Peltier [1994]. The anomalies between climatic fields for these two time slices are superimposed on the reference climatologies used by the mass balance model. Over a glacial cycle the surface temperature is given by

$$
\begin{aligned}
T_{\text {mon }}^{\text {sur }}(\phi, \lambda, t)= & {\left[T_{U K M O}^{s l}(\phi, \lambda, L G M)-T_{U K M O}^{s l}(\phi, \lambda, P D)\right] \beta(t)^{n} T_{r} } \\
& +T_{N C E P}^{s l}(\phi, \lambda, P D)+\gamma_{l} H^{\text {sur }}(\phi, \lambda, t)
\end{aligned}
$$

where the monthly mean surface temperature is specified as a function of time $t$ and location $(\phi, \lambda)$. The temperature difference appearing in the first term of the right-hand side of equation (13) is the UKMO GCM modeled monthly mean temperature difference between the LGM and PD, reduced to sea-level with the atmospheric lapse rate specified in Table 1. $T_{r}$ is a rescaling factor used in the sensitivity study to examine changes in the ice sheet resulting from differences in the glacial-interglacial temperature anomaly. The observed present day temperature has been derived from NCEP reanalysis of monthly mean temperatures provided by the NOAA-CIRES Climate Diagnostics Center for the period from 1968 to 1996 [Kalnay et al., 1996], and is reduced to sea level as a reference level for the dynamic changes in topography caused by the ice sheet evolution. The mean temperature difference for the summer months (June-July-August) is shown in Figure 3. When deriving these fields, it turned out to be necessary to modify the temperature over regions where LGM ice sheets occupied what are now oceanic regions (Hudson Bay, Barents Sea). This is to remove artifacts relating to the different summer warming over oceanic and continental regions for the present climate, and was accomplished by interpolation from neighbouring areas 
that did not have this problem. The surface elevation needed in equation (13) is either taken as the elevation of the ice sheet or of the highest point within each grid cell for the present topography. This is because the glaciation threshold is to a large extent determined by the most elevated terrain, which is a piece of information that is otherwise lost when values are averaged on the $50-\mathrm{km}$ grid. Bed topographies were generated from the ETOP05 data set.

[25] To use these time slice fields over an entire glacial cycle, we consider them as extremes in the glacial/interglacial climate contrast, and use a normalized glacial index $\beta(t)^{n}$ [Marshall et al., 2000] derived from a synthesized GRIP $\delta^{18} \mathrm{O} /$ Vostok deuterium record [Huybrechts, 2002] at a 100-year resolution for rescaling. The glacial index is defined to be 1 at LGM (taken at $21 \mathrm{ka}$ cal BP) and 0 at the present day. As shown in Figure 2 this record introduces a relatively high temporal variability into the climate forcing [Marshall et al., 2000]. For the reference model the value of the exponent is set at 1 , but this value is allowed to vary in the sensitivity study. It controls the degree to which the time slices are linearized to represent intermediate climate states between the two end members.

[26] The treatment of precipitation is similar to that of temperature, except that the ratio of LGM and present-day time slices is used and not the difference. This is because using the same form of equation (13) for precipitation might introduce 'negative precipitation' into the climate forcing, which has no physical basis. The appropriate relation reads:

$$
\begin{aligned}
P(\phi, \lambda, t)= & \left\{\left[\frac{P_{U K M O}(\phi, \lambda, L G M)}{P_{U K M O}(\phi, \lambda, P D)}-1\right] \beta(t)^{n} P_{r}+1\right\} \\
& \cdot P_{\text {Jaeger }}(\phi, \lambda, P D)
\end{aligned}
$$

where the yearly precipitation rate distribution is also given as a function of time and location, and $P_{U K M O}(\phi, \lambda, L G M) /$ $P_{U K M O}(\phi, \lambda, P D)$ is the ratio of UKMO GCM modeled annual precipitation between LGM and the present day (Figure 3). No correction for precipitation relating to topographic differences between LGM and PD is made as it is assumed that the elevation desert effect is already embedded within the precipitation anomalies. $P_{r}$ is a rescaling factor of the precipitation anomaly used in the sensitivity study. The observed precipitation comes from Jaeger [1976]. Other precipitation distributions from Legates and Willmott [1990], the German Weather Service (DWD), and Kalnay et al. [1996] were also examined. However, the data set from Jaeger provides the most realistic present day ice sheet extent when used with the ice sheet model in steady state mode.

[27] The approach adopted here is probably the best one can do as long as interactive coupling of ice-sheet models with GCMs remains technically unfeasible. It cannot answer the question of what caused the ice ages and which feedbacks between the ice sheets and the climate system actually amplified and modified the initial pacing that is widely believed to be of astronomical origin [Hays et al., 1976; Imbrie et al., 1984]. But it allows to account for changes in the patterns of climate change while at the same time representing the present-day climate from observations, which are superior to that which current GCMs are able to produce, even at resolutions higher than the UKMO model. The approach therefore constitutes a step forward compared to earlier treatments which had to assume uniform temperature perturbations and had to make precipitation a function of temperature [e.g., Huybrechts and T'siobbel, 1995; Greve et al., 1999]. It may also make it unnecessary to introduce uncertain dependencies such as the elevation desert effect as this dependency is usually already embedded within the model physics of the GCM. A disadvantage of having only two time slices, on the other hand, is that climatic patterns corresponding to ice-sheet configurations intermediate between the LGM and PD are not optimally represented. Since the ice sheets basically migrated latitudinally, so did modifications to the atmospheric circulation and hydrological cycle caused by ice-sheet induced changes in the position of the jet stream and orographic precipitation. The use of more time slices can be helpful to refine the method [Charbit et al., 2002], but even then interpolation of the climate fields is necessary to force the ice sheet model in a transient manner.

\section{Reference Model Run}

[28] We first document the results of a reference model run that is to serve as a basis for model comparison when changes to the ice sheet model parameters are made. For this reference model, we chose model parameters on the basis of good agreement between model output and observations. Most weight was given to consistency with geomorphological inferences of LGM ice extent, ice volume estimates from observed sea level changes and PD ice sheet coverage. Model parameters are chosen identical for all ice masses of the northern hemisphere. Although the approach with uniform parameters has been shown to be problematic, e.g., to model the Laurentide ice sheet with PD Greenland ice sheet rheological parameters [e.g., Tarasov and Peltier, 2000], we have insufficient observational evidence to justify making a clear distinction between the physics of the separate ice masses on the North American and Eurasian continents. Additionally, the Greenland ice sheet only played a modest role in global sea level changes during the last ice age ( 3 m maximum [e.g., Huybrechts, 2002]), and therefore should not be the focus for optimizing model parameters. The standard model values are listed in Table 1.

[29] Figure 4 shows time-dependent predictions over a glacial cycle using initial conditions of a glaciological steady state ice configuration forced by PD climate. Figure $4 \mathrm{a}$ shows that the maximum volume of ice generated over this period attains a value of $57 \times 10^{6} \mathrm{~km}^{3}$, or about $54 \times 10^{6} \mathrm{~km}^{3}$ higher than the current ice volume, of which $35 \times 10^{6} \mathrm{~km}^{3}$ is stored in North America, $18 \times 10^{6} \mathrm{~km}^{3}$ in Eurasia and another $4 \times 10^{6} \mathrm{~km}^{3}$ in Greenland/Iceland (Figure 4c). The remaining ice volume at the present time of about $3 \times 10^{6} \mathrm{~km}^{3}$ is in the model mostly stored in the Greenland ice sheet $\left(2.7 \times 10^{6} \mathrm{~km}^{3}\right)$, with only $0.06 \times$ $10^{6} \mathrm{~km}^{3}$ in North America and $0.017 \times 10^{6} \mathrm{~km}^{3}$ in Eurasia. The maximum ice volume occurs at $18.5 \mathrm{ka}$ cal BP. That is almost 500 years later than what is thought to be the end of the LGM based on observations of eustatic sea level change [Yokoyama et al., 2000]. Such a delay appears to be an inherent feature of northern hemisphere ice sheet 

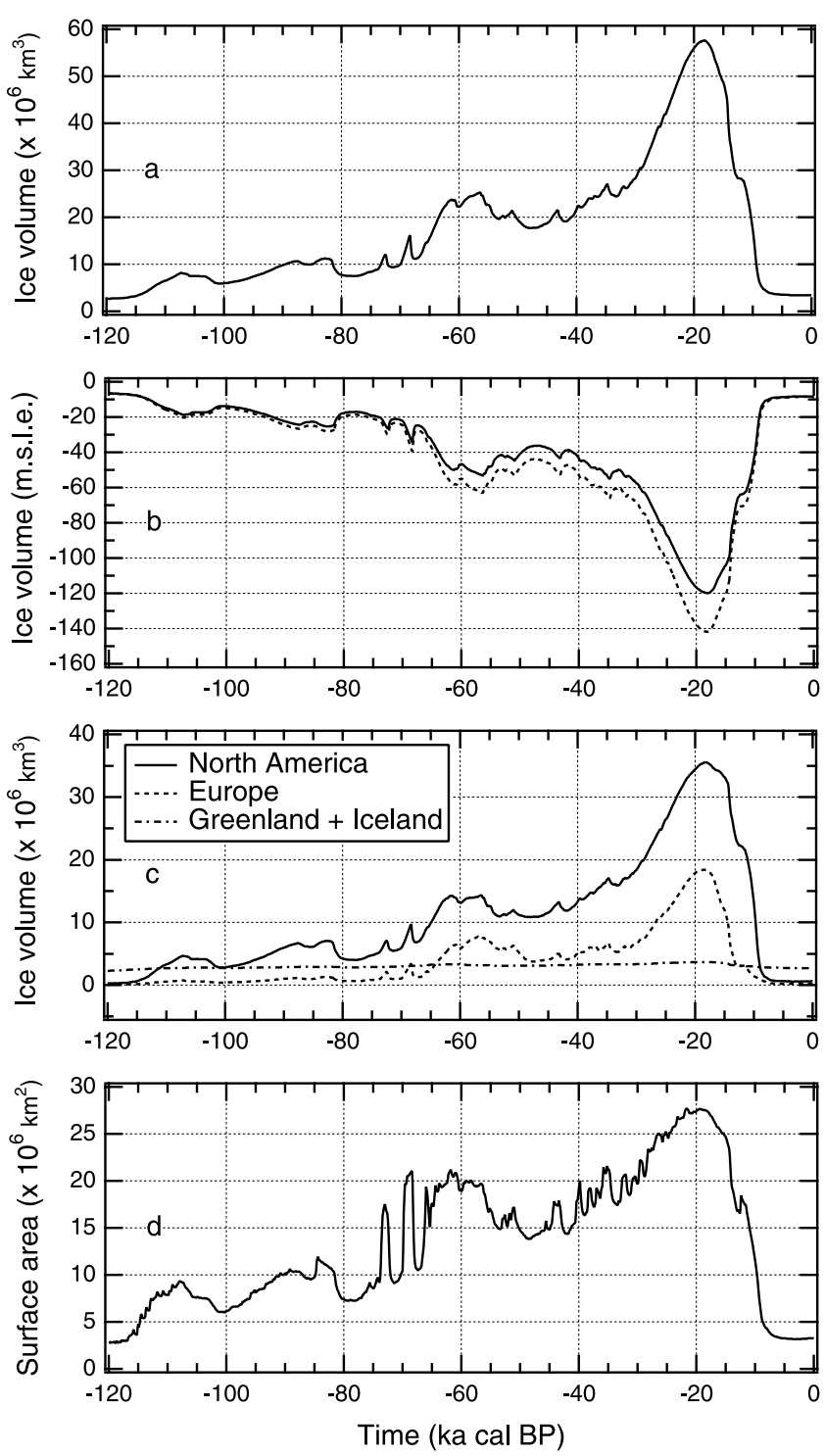

Figure 4. Time-dependent change in basic model outputs for the reference model run. (a) Total ice sheet volume over the last glacial cycle. (b) Total ice sheet volume converted to change in eustatic sea level from the present day (dashed line) and corrected sea level change using the method described in the text (solid line). (c) Total volumes of ice sheets by region as listed in the legend. (d) Total ice sheet surface area.

models both with [e.g., Marshall et al., 2002; Bintanja et al., 2002] and without [e.g., Charbit et al., 2002] GRIP ice core based forcing. It probably indicates shortcomings in the model forcing at that time, or alternatively, a too large phase lag introduced by the coupled ice-sheet/lithosphere dynamics.

[30] In Figure 4b, the modeled northern hemisphere icesheet volume is converted into eustatic sea-level contributions. The conversion takes into account the changes in volumetric capacity of the northern hemisphere ocean basins as ice replaces ocean water, while considering a fixed oceanic area of $3.98 \times 10^{8} \mathrm{~km}^{2}$, or $71 \%$ of the Earth's surface. For purposes of estimating a geomorpho- logically accurate contribution to eustatic sea level from the Northern Hemisphere ice sheets at the LGM, the full line in Figure $4 \mathrm{~b}$ is additionally corrected for anomalous ice cover occurring outside of the geomorphologicallyinferred LGM extent shown in Figure 1. Disregarding all of the anomalous ice volume, we find a maximum eustatic sea level change from the present day of $110 \mathrm{~m}$, distributed among the different ice sheet complexes as $82.1 \mathrm{~m}$ (North America), $25.4 \mathrm{~m}$ (Eurasia), $2.1 \mathrm{~m}$ (Greenland) and $0.4 \mathrm{~m}$ (Iceland). Without the geomorphological correction, the total value is about $133 \mathrm{~m}$, as shown by the stippled line in Figure 4b. Combined with the 19 to $24 \mathrm{~m}$ of eustatic sea level from sources outside the model domain (mainly Antarctica and Patagonia [cf. Clark and Mix, 2002]), the geomorphologically corrected model results is fully compatible with most estimates of the magnitude of eustatic sea level change since the LGM of $130 \mathrm{~m}$.

[31] Another characteristic evident from the curves shown in Figure 4 is the slow build-up of northern hemisphere ice volume prior to the LGM. Between 120 and $110 \mathrm{ka}$ cal BP the observational record of sea level change shows a fast reduction in sea level of between $50 \mathrm{~m}$ (SPECMAP, Figure 2) and $60 \mathrm{~m}$ [Lambeck and Chappell, 2001] which is not reproduced by the model. This is possibly a result of inaccuracies in the GRIP forcing for this time period, but since the GRIP-derived glacial index sharply rises to a value of 0.8 during the inception, we must conclude that our climate forcing probably misses additional processes favorable for fast ice-sheet growth. Likely candidates are much higher precipitation rates during inception than those obtained by scaling the LGM to PD precipitation rate, perhaps as a consequence of continued warm surface conditions in the north Atlantic into much of MIS 5d [McManus et al., 2002]. Other studies indicate missing feedbacks from terrestrial and oceanic processes [Meissner et al., 2003] or between Arctic sea ice and the biosphere [Crucifix and Loutre, 2002] to amplify high-latitude cooling during glacial inception. Figure 4 also shows that for the period prior to about $30 \mathrm{ka}$ cal BP only half of the maximum volume is reached. On first view, this also seems to contradict the form of the sea-level forcing itself, if it is assumed that the SPECMAP stack (derived from benthic $\delta^{18} \mathrm{O}$ ) is a linear reflection of total ice volume. It also seems at odds with the inference made by Svendsen et al. [1999] about an ice sheet maximum in the Kara Sea taking place during the early to mid Weichselian. However, other interpretations of ice volume evolution prior to the LGM more in accord with our findings have been made [Winograd, 2001]. Also, our modeled ice sheet area (Figure 4d) shows maxima between 70 and $60 \mathrm{ka}$ cal BP that are up to $80 \%$ of the LGM maximum. Apparently, during the early phase of glaciation ice sheet area increased relatively faster than the ice thickened, implying that total volume is a less meaningful indicator of total glaciation. A related remark is that ice sheet area responds much more quickly to the climate forcing than total ice volume, the latter of which hardly shows the effects of stadials and interstadials in accord with the SPECMAP sea-level record. This can be explained by the immediate control of marginal ablation on ice sheet extent, whereas total volume is governed by slower processes such as glacial dynamics and temporally integrated total mass balance. 


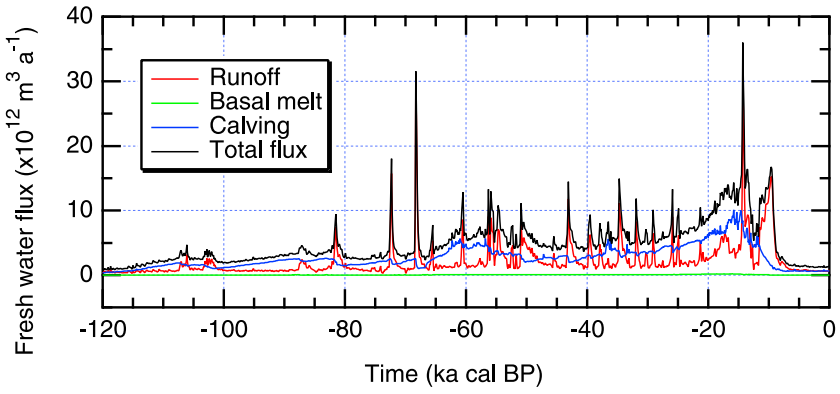

Figure 5. Components of the total freshwater flux originating from the northern hemisphere ice sheets during the last glacial cycle. Values are expressed in $\mathrm{m}^{3} \mathrm{a}^{-1}$ of water equivalent.

[32] Figure 5 shows the fresh water fluxes from the northern hemisphere ice sheets during the last glacial cycle. This is an important characteristic because of its role in modulating the deep-water circulation of the oceans. It can be seen that for most of the last glacial cycle calving is the dominant component, typically representing $50-80 \%$ of the total ice volume loss. The remainder is mainly made up by surface runoff. Basal melting from below the ice sheet is insignificant, and generally 2 to 3 orders less important in volume. A striking feature of the temporal evolution of the fresh water fluxes are peaks of up to 10 times larger than the regular fresh water output. These peaks occur during warm intervals and are entirely caused by rather spectacular increases in surface melting, usually following a cold period of ice sheet advance. The peaks typically last a few hundred years and are all associated with important reductions of ice sheet surface area by up to $50 \%$ (Figure $4 \mathrm{~d}$ ). The most important events occurred at $72.3 \mathrm{ka}, 68.3 \mathrm{ka}$, and $14.3 \mathrm{ka}$ cal BP, and were all followed by large cooling shifts in the climatic forcing. The largest freshwater pulse occurred just before the onset of the Younger Dryas cooling. Smaller peaks were associated with the warming legs of DansgaardOeschger events. The only period of dominant sustained surface melting during the last glacial cycle, responsible for $70-95 \%$ of the total freshwater flux, occurred between 12 and $9 \mathrm{ka}$ cal BP and was mainly associated with the disintegration of the North American ice sheet.

[33] Time slices of modeled ice surface elevation at various moments during the last glacial cycle are presented in Figure 6. The initial configuration for $120 \mathrm{ka}$ cal BP was produced under steady state PD conditions. This configuration at the same time serves as validation for the model. The simulation is quite realistic. The Greenland ice sheet is well reproduced, albeit somewhat thinner than observed because of our specific choice of the rate factor, but also the smaller ice masses around the Arctic perimeter and in major mountain areas are simulated in almost the same locations as they are observed today. This means that the mass balance model is able to correctly identify areas with a positive mass balance and that topographical control on glacier inception is satisfactorily incorporated. The only deviation from reality concerns the merger of small ice masses to fill one or several grid cells in parts of Arctic Canada and the Rockies, as the model cannot represent glaciers at sub gridscale resolution.
[34] Subsequent snapshots for $80 \mathrm{ka}$ and $50 \mathrm{ka}$ cal BP show the locations of inception centers from where major ice sheets spread and eventually merged into larger ice sheets. In North America, three separate ice sheets build up over the coastal Rockies, the Canadian Arctic Islands, and the Ungava Peninsula/Labrador plateaus to respectively form the Cordilleran, Innuitian, and Laurentide ice sheet. In Eurasia, the model simulates glaciation centers located over the Norwegian mountains, the Arctic islands, and the Putorana mountains, from where they spread across the Barents Sea during later stages of the last glacial period. Other glaciation centers were located in Iceland, the Alps, the Scottish highlands, and high terrain in eastern Siberia and the Kamtchatka Peninsula, in good agreement with the geological record. The model performs somewhat less well in separating the Cordilleran and Laurentide ice sheets until close to the LGM and the expansion of ice in Siberia, which must probably be attributed to shortcomings in the simple and spatially constant climate anomaly forcing imposed during the glacial buildup.

[35] The extent of the LGM ice sheets shown in Figure 6 for $21 \mathrm{ka}$ cal BP corresponds quite closely with that observed by the geomorphology. The main exception is excessive glaciation over the Kara Sea and the Taimyr Peninsula, as evident from the Quaternary Environment of the Eurasian North (QUEEN) project results shown for this region in Figure 1 [Svendsen et al., 2004a]. This is thought to result from the climate input into the ice sheet model, as the PMIP simulations use the $21 \mathrm{ka}$ cal BP ice sheet elevation from the ICE-4G deglaciation chronology of Peltier [1994] as an LGM boundary condition. Figures 3 and 6 show that the model predicted LGM ice sheet extent is roughly correlated with the $-12^{\circ} \mathrm{C}$ isotherm of summer temperature anomaly from the UKMO model. This suggests that the LGM ice sheets appear largely 'imprinted' in the UKMO climate anomalies, presumably due to albedorelated cooling over the surface of the former ice sheets. Also the precipitation reduction in northern Siberia is less severe than often suggested [Siegert et al., 2001], and this too promotes further eastward expansion of ice than indicated by the geological record. There is some evidence for glaciation over the northern islands off the Taimyr Peninsula [Knies et al., 2001], but not to the extent shown in Figure 6 [Mangerud et al., 1999]. In most other regions the model predicted LGM extent is consistent with the observational record, with Alaska and Siberia predominantly ice free and locations of the southern margins of the Laurentide and Fennoscandian ice sheets approximately in accord, although fine scale features such as the southern lobes of the Laurentide ice sheet [Dyke et al., 2002, Figure 1] are not reproduced by the model. The structure of these lobes is consistent with fast flow processes caused by increased basal sliding or sediment deformation enhancement, processes which are not included in the ice sheet model.

[36] The distribution of ice thickness and surface elevation at LGM, on the other hand, can only be evaluated within the imposed constraints that our reconstruction satisfies a total eustatic sea-level depression of $\sim 110 \mathrm{~m}$ within the geomorphologically inferred LGM ice sheet extent of Figure 1, and that glaciological model parameters do not vary between the different ice sheet complexes. As a result, total ice volume is about $50 \%$ larger than the ICE-4G 

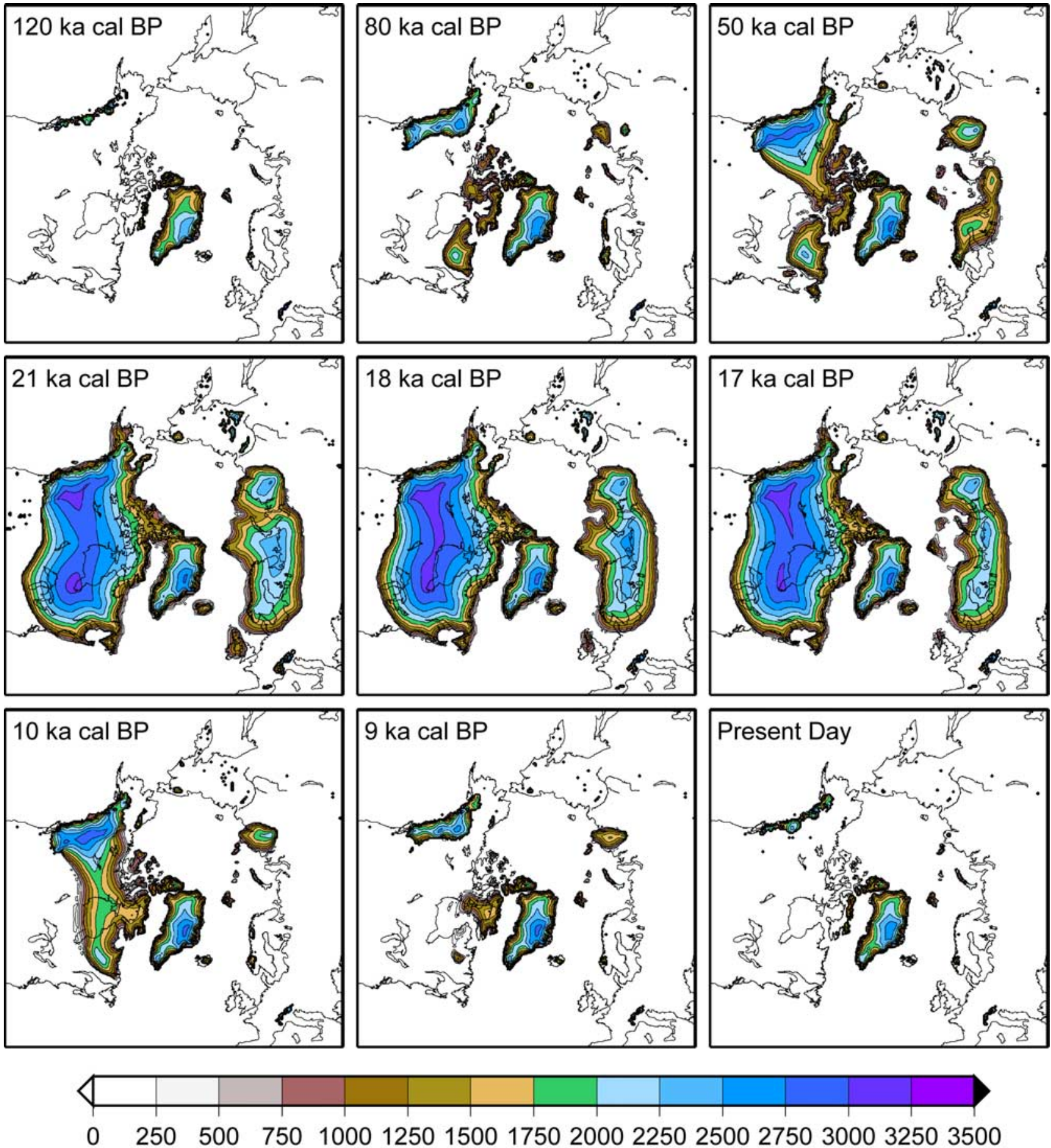

Figure 6. Evolution of ice sheet elevation (m) during the last glacial cycle for the reference model. Times are given in each panel.

reconstruction for a roughly similar extent. Proportionally, the thickening with respect to ICE-4G is largest for the Fennoscandian ice sheet, but also the maximum surface elevation of the Laurentide ice sheet is above $3000 \mathrm{~m}$ in central areas, in contrast to the 2000 to $2500 \mathrm{~m}$ indicated by ICE-4G. For the Laurentide ice sheet the ICE4-G values are, however, again in strong contrast with the $4500 \mathrm{~m}$ maximum surface elevation of the recent ICE-5G reconstruction [Peltier, 2004] based on new VLBI and temporal gravity change data from central Canada [Pagiatakis and Salib,
2003]. A major revision of ICE-5G with respect to ICE-4G is the presence of a thick Keewatin dome suggesting a multiple domed configuration for the North American ice sheet, whereas the results presented here reconstruct this ice sheet as a bidomal structure with maxima over Hudson Bay and the Rockies. Tarasov and Peltier [2004] attribute their multiple domed structure to enhanced basal flow resulting from the deformation of soft sediments and the introduction of ice streaming at the base of the ice sheet, but Marshall et al. [2002] do not find this enhancement to be an essential 

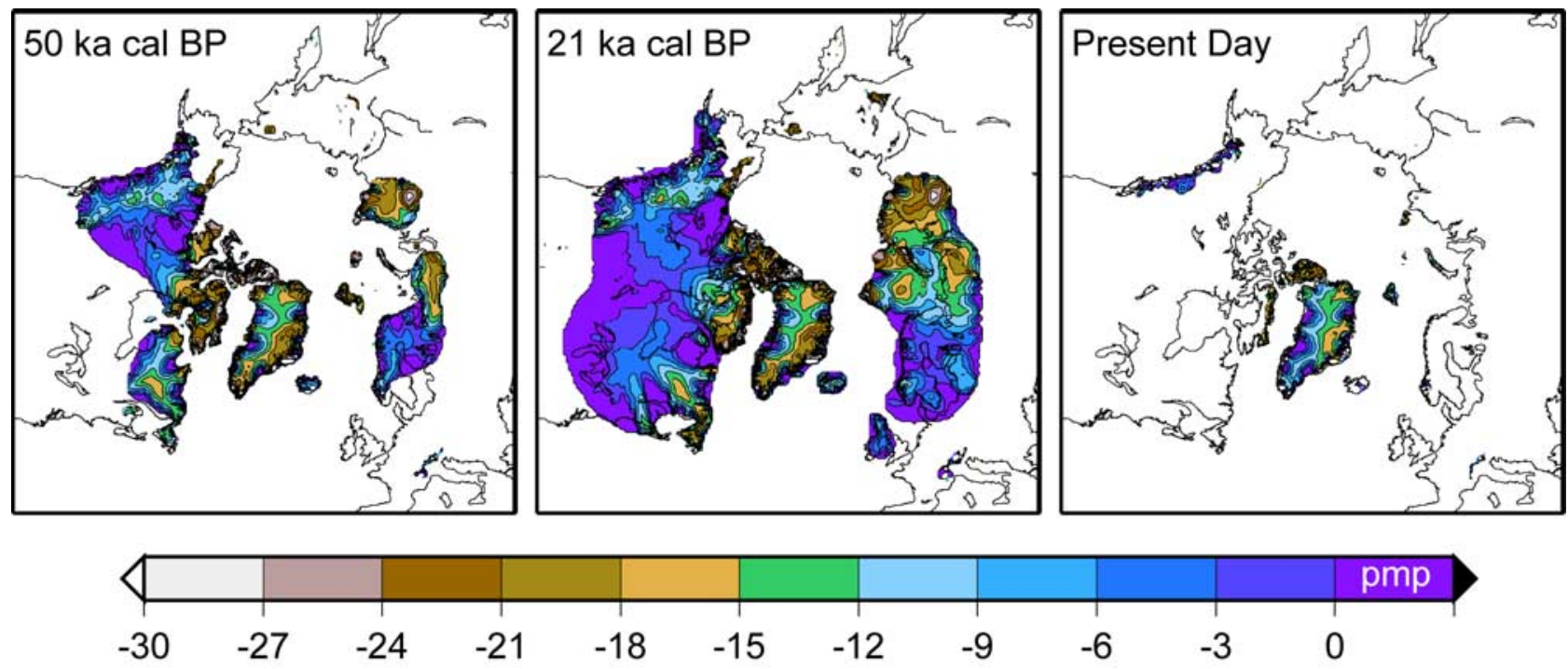

Figure 7. Evolution of basal ice temperature $\left({ }^{\circ} \mathrm{C}\right.$ relative to pressure melting point) during the last $50 \mathrm{ka}$ for the reference model. Times are given in each panel.

precondition to produce a multiple domed Laurentide ice sheet. We find here that the exact domal structure of the Laurentide ice sheet is a rather ephemeral feature. For the Fennoscandian ice sheet, ICE-5G more closely resembles ICE-4G except for a revision in extent in the Kara Sea which is more in line with recent geomorphological observations [Svendsen et al., 2004a].

[37] Figure 6 shows the marine infiltration of the Barents Sea by $17 \mathrm{ka}$ cal BP and Hudson Bay by $9 \mathrm{ka}$ cal BP. The marine extent parameterization was chosen so as to reproduce the observed changes in marine extent at these locations as closely as possible [Landvik et al., 1998; Dyke et al., 1989; Zweck and Huybrechts, 2003], although a recent revision of the observational data for the Barents Sea suggests a later marine infiltration (14 ka cal BP) than assumed here [Svendsen et al., 2004b]. Together with the largely increased melting rates associated with the Holocene warming, the model is able to reproduce a full return to interglacial ice-free conditions, with only the Greenland ice sheet surviving as a major ice mass. The complete removal of marine ice bodies on the Arctic continental shelf during the deglaciation is in contrast to other model studies that do not incorporate a treatment for marine ice/ocean interaction [e.g., Greve et al., 1999; Charbit et al., 2002]. The modeled $\mathrm{PD}$ ice sheet elevation shown in Figure 6 is generally consistent with the observations, although the extent in British Columbia and Alaska is too great. We attribute this to the coarse resolution of the ice sheet model which is unable to reproduce the steep topography in this region.

[38] Figure 7 shows time slices of model predicted basal ice temperature relative to pressure melting point since $50 \mathrm{ka}$ cal BP. The general pattern displays cold-based conditions in the interior of the ice sheets with ice at pressure melting mostly confined to the ice-sheet margins where heat generated by dissipation and surface temperatures are highest. This is quite similar to patterns inferred for the present-day Greenland and Antarctic ice sheets [e.g., Huybrechts, 1990, 1996]. A remarkable feature of the simulations is that by $21 \mathrm{ka}$ cal $\mathrm{BP}$ most of the southern half of the Laurentide and western part of the Fennoscandian ice sheets are at pressure melting point at their bases. This can be partly explained by the insulating effect of the thickening ice but also has a component arising from the surface temperature forcing. This time dependent change from generally frozen to generally wet bed conditions near the LGM has been suggested as a potential mechanism to explain the relatively fast retreat of the ice sheets since the LGM because of the enhancing effect it has on ice fluxes [Marshall and Clark, 2002]. The realism of our basal temperature fields is, however, hard to judge but seems to be supported by some indirect evidence. The inferred existence of peripheral low-sloping lobes of the Laurentide ice sheet [Marshall and Clark, 2002] and inferred palaeo-temperatures from boreholes [Rolandone et al., 2003] both indicate basal thawing along the southern margin of the North American ice sheet. Ribbed moraine structures investigated by Kleman and Hättestrand [1999] indicate frozen-bed conditions for the northern half of the North American ice sheet and over the Norwegian mountains, which is also supported by our simulations.

\section{Sensitivity Study}

[39] As ice sheet models integrate the effects of various processes forward in time, the relative importance of model physics and parameters are difficult to discern in a single model run. To investigate the sensitivity of the model, we therefore make changes to single model parameters and examine the differences in model output from that of the reference model. We concentrate on the most poorly known parameters and systematically apply step changes over what we consider realistic parameter ranges. The model parameters are grouped into five different components of the ice sheet model. We group them as those relevant to climate processes (group $\mathrm{C}$ ), rheological processes (R), basal processes (B), isostatic adjustment processes (I), and marine calving processes $(\mathrm{E})$. An overview of the parameters tested 
Table 2. Summary of Sensitivities of Model Outputs to Various Model Parameters ${ }^{\mathrm{a}}$

\begin{tabular}{|c|c|c|c|c|c|c|c|c|c|c|c|}
\hline Parameter & $P_{r}$ & \multirow[t]{2}{*}{$T_{r}$} & \multirow[t]{2}{*}{$P D D F S$} & \multirow[t]{2}{*}{$\sigma$} & \multirow[t]{2}{*}{$n$} & $m_{r}$ & $\gamma$ & \multirow[t]{2}{*}{$A_{s}$} & $\tau$ & \multirow[t]{2}{*}{$D$} & \multirow{2}{*}{$\begin{array}{c}H_{c} \\
\text { Marine } \\
\text { Calving }\end{array}$} \\
\hline Group & Climate & & & & & Rheology & $\begin{array}{c}\text { Basal } \\
\text { Processes }\end{array}$ & & $\begin{array}{l}\text { Glacial } \\
\text { Isostasy }\end{array}$ & & \\
\hline Example runs & $\mathrm{C} 2, \mathrm{C} 3$ & $\mathrm{C} 1, \mathrm{C} 4$ & $\mathrm{C} 5, \mathrm{C} 8$ & $\mathrm{C} 6, \mathrm{C} 7$ & $\mathrm{C} 9 \rightarrow \mathrm{C} 12$ & $\mathrm{R} 2, \mathrm{R} 3$ & $\mathrm{~B} 2, \mathrm{~B} 3$ & $\mathrm{~B} 1, \mathrm{~B} 4, \mathrm{~B} 5$ & $\mathrm{I} 1 \rightarrow \mathrm{I} 4$ & I5,I6 & $\mathrm{E} 1 \rightarrow \mathrm{E} 3$ \\
\hline \multicolumn{12}{|c|}{ Model Parameter Reference Values, Ranges, and Resolution of Parameter Space Search } \\
\hline Reference value & 1 & 1 & 1 & 5 & 1 & 1 & 1 & $1.8 \times 10^{-11}$ & 3000 & $1 \times 10^{25}$ & 5 \\
\hline Minimum & 0.75 & 0.75 & 0.5 & 4.5 & 0.5 & 0.15 & 0.5 & $1.8 \times 10^{-13}$ & 300 & $1 \times 10^{24}$ & 4 \\
\hline Maximum & 1.25 & 1.25 & 1.5 & 5.5 & 1.5 & 5 & 1.5 & $1.8 \times 10^{-8}$ & 30000 & $1 \times 10^{26}$ & 6 \\
\hline Resolution & 0.025 & 0.025 & 0.05 & 0.05 & 0.05 & $\log _{10}(1.192)$ & 0.05 & $\log _{10}(1.778)$ & $\log _{10}(1.259)$ & $5 \times 10^{23}$ & 0.1 \\
\hline Spacing & linear & linear & linear & linear & linear & $\log$ & linear & $\log$ & $\log$ & linear & linear \\
\hline \multicolumn{12}{|c|}{ Maximum Ice Volume } \\
\hline $10 \%$ change $(\%)$ & -2.9 & 18.7 & -6.8 & -5.6 & -1.5 & -3.2 & -1.0 & -0.2 & 0.3 & -0.4 & 3.2 \\
\hline $\mathrm{R}^{2}$ & 0.98 & 0.92 & 0.99 & 0.97 & 0.90 & 0.99 & 1.00 & 0.61 & 0.89 & 0.81 & 0.80 \\
\hline Total change $(\%)$ & -14.5 & 93.3 & -67.8 & -11.2 & -14.7 & -49.0 & -10.0 & -11.0 & 6.7 & -3.3 & 12.9 \\
\hline \multicolumn{12}{|c|}{ Time of Maximum Ice Volume } \\
\hline $10 \%$ change $(a)$ & 317 & -343 & 150 & 643 & 159 & -8 & -32 & 0.2 & -51 & 9 & 42 \\
\hline $\mathrm{R}^{2}$ & 0.90 & 0.73 & 0.66 & 0.93 & 0.87 & 0.18 & 0.49 & 0.01 & 0.72 & 0.02 & 0.03 \\
\hline Total range (a) & 1584 & -1719 & 1499 & 1286 & 1592 & -118 & -319 & 11 & -1012 & 79 & 166 \\
\hline \multicolumn{12}{|c|}{ Maximum Surface Area } \\
\hline $10 \%$ change $(\%)$ & -1.6 & 12.1 & -4.6 & -4.5 & -0.2 & -0.3 & 0.0 & -0.0 & 0.4 & -0.1 & 1.1 \\
\hline $\mathrm{R}^{2}$ & 0.99 & 0.92 & 1.00 & 0.99 & 0.67 & 0.90 & 0.05 & 0.71 & 0.89 & 0.57 & 0.92 \\
\hline Total range $(\%)$ & -7.8 & 60.5 & -46.5 & -9.0 & -2.1 & -4.9 & 0.1 & -1.8 & 7.8 & -1.3 & 4.6 \\
\hline \multicolumn{12}{|c|}{ Maximum Mean Ice Sheet Thickness } \\
\hline $10 \%$ change $(\%)$ & -1.1 & 7.4 & -1.9 & -0.8 & -0.7 & -2.9 & -1.0 & -0.2 & 0.0 & -0.2 & 2.8 \\
\hline $\mathrm{R}^{2}$ & 0.91 & 0.88 & 0.85 & 0.62 & 0.84 & 0.99 & 1.00 & 0.56 & 0.03 & 0.72 & 0.79 \\
\hline Total range $(\%)$ & -5.6 & 37.0 & -19.2 & -1.7 & -6.6 & -44.0 & -10.3 & -8.0 & 0.3 & -1.9 & 11.1 \\
\hline
\end{tabular}

${ }^{a}$ Model parameters, their role, and example runs are listed in the upper rows, followed by an overview on how the parameter space of each model parameter is charted. The lower four blocks show the modeled sensitivity of Last Glacial Maximum (LGM) ice volume, time of maximum ice volume, maximum surface elevation, and maximum mean surface ice thickness. Listed are the change from the reference model run for a $10 \%$ change in model parameters, the correlation coefficient $\left(\mathrm{R}^{2}\right)$ of a linear least squares fit, and the total range of model response for the range over which the model parameter was investigated. The sensitivities in this table are also shown graphically in Figure 11.

and their ranges is given in Table 2. Main results of the sensitivity tests are displayed in Figures 8 and 9. In this section we first concentrate on qualitative aspects. Features of interest include ice volume evolution, LGM extent, timing of maximum ice volume, and maximum mean ice sheet thickness.

\subsection{Climate Processes}

[40] The sensitivity to the atmospheric forcing is tested by modifying the magnitude of climate differences between LGM and PD as represented by the UKMO GCM, and by variations of the glacial index exponent $n$ that control the strength of the atmospheric forcing during periods of intermediate climate. The atmospheric forcing affects the ice sheet mass balance through changes in snow accumulation and meltwater runoff, the latter of which is controlled by the positive degree day formulation.

\subsubsection{Input Climate Data}

[41] As shown above, the inclusion of palaeo and present day GCM model output to reconstruct the climate forcing is able to generate an ice sheet history that is generally in accord with geomorphological data. This has also been demonstrated in other studies [e.g., Charbit et al., 2002; Marshall et al., 2002], and is mostly due to the strong dependence of temperature on albedo in the GCM physics. As a result of this the ice sheets that were originally embedded in the GCM appear 'imprinted' in the climate anomalies. However, Pollard et al. [2000] conclude that the different GCMs which participated in PMIP generate widely divergent mass balance estimates. The UKMO GCM output is thus only one possible climate result and may therefore be varied within certain bounds. We explore the sensitivity of this data to the ice sheet model by making changes to $T_{r}$ and $P_{r}$ over a range of $25 \%$ of their reference value. The magnitude of changes in these parameters is designed so that the $12^{\circ} \mathrm{C}$ isotherm of temperature anomaly, which roughly coincides with the ice-sheet margin, changes by about $\pm 3^{\circ} \mathrm{C}$. This $6^{\circ} \mathrm{C}$ is approximately equal to the range of summer air temperatures over the ablation zones found in the different PMIP outputs [Pollard et al., 2000].

[42] The resulting time-dependent changes in ice sheet volume are shown in Figure 8a. For the same percentage changes of the climate fields, temperature is a stronger control on ice sheet evolution than precipitation. This result is in accord with that of Pollard et al. [2000], who conclude that the largest source of divergence in calculated mass balance is the summer surface air temperature over the ablation zones. However, the sensitivity of precipitation in the model also depends on its implementation, as Marshall et al. [2002] determine that when an elevation desert precipitation effect is included the exact form of the parameterization is the most sensitive parameter for the ice sheet model. We do not include an elevation desert effect here, as it is our view that it should already have been included in the GCM precipitation fields, although Pollard 

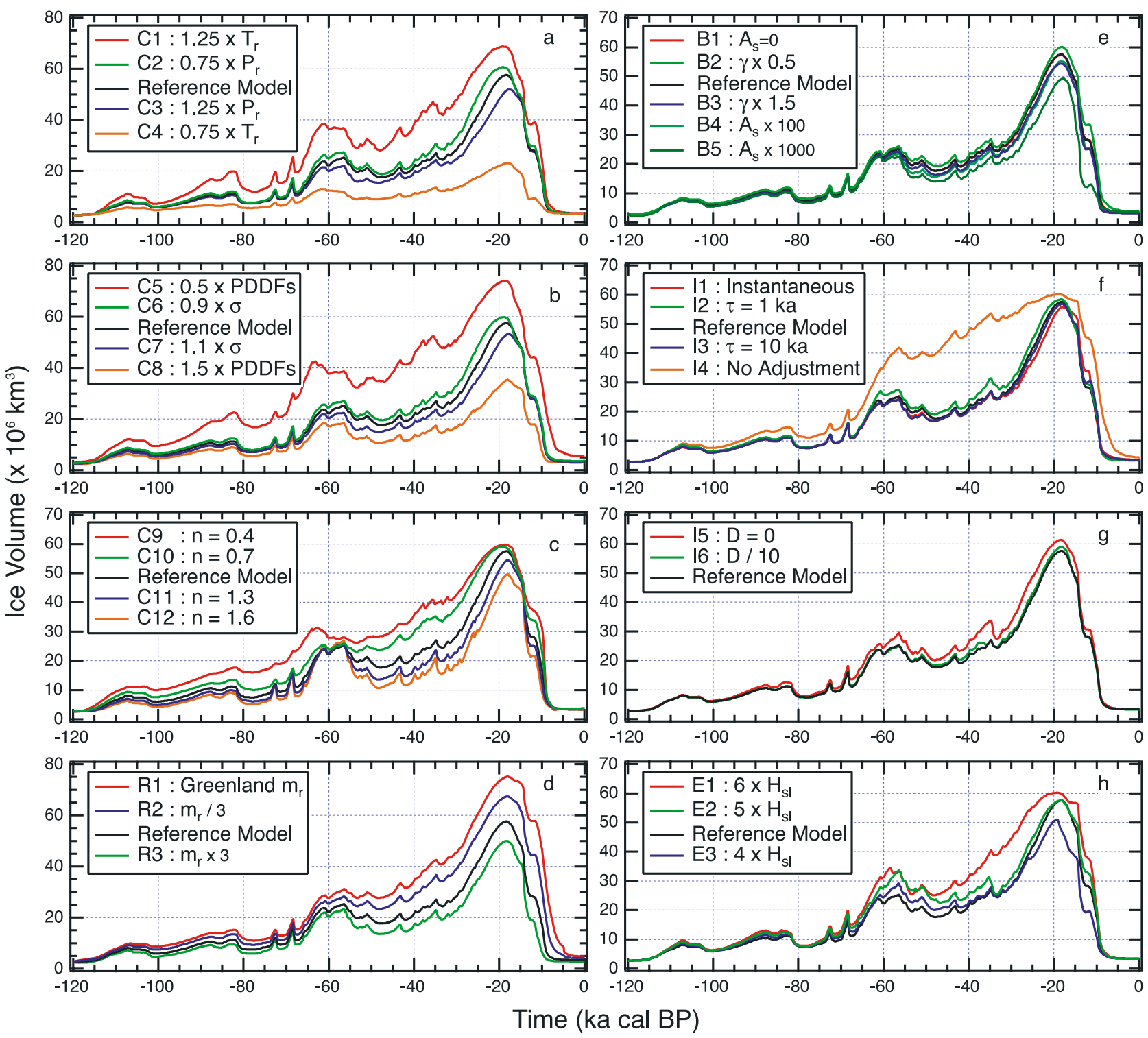

Figure 8. Time dependent change in total ice sheet volume for the sensitivity model runs described in the text. (a-c) Model sensitivity to changes in climate forcing. (d) Model sensitivity to rheology. (e) Model sensitivity to basal processes. (f and g) Model sensitivity to glacial isostasy. (h) Model sensitivity to the marine calving parameterization.

et al. [2000] conclude that it is not a strong feature of the PMIP results for the LGM.

[43] Experiments $\mathrm{C} 1$ and $\mathrm{C} 4$ in Figure 9 show LGM ice sheet surface elevations when $T_{r}$ is modified from its reference value by $\pm 25 \%$. It shows that changes in the UKMO PMIP temperature anomaly of this magnitude produce substantial changes in the LGM ice extent and volume. Reducing the summer temperature anomaly by approximately $3^{\circ} \mathrm{C}$ (experiment $\mathrm{C} 4$ ) produces LGM ice sheets that are about $50 \%$ of those in the reference experiment. Conversely, increasing the LGM summer cooling by $25 \%$ (experiment $\mathrm{C} 1$ ) increases surface area and ice volume by respectively 13 and $19 \%$. This asymmetry with respect to the reference state is a result from the height-mass balance effect and the circular pattern of summer temperature change, which is highest along the ice-sheet margin of the PMIP LGM ice sheets. This prohibits large increases of surface area but promotes retreat of ice sheets smaller than the PMIP ice sheets on which the anomaly patterns were based.

\subsubsection{Positive Degree Day Formulation}

[44] The positive degree day factors relate the surface temperature to the magnitude of the snow and ice melt. They can therefore be expected to constrain the ice sheet extent and volume in a similar way as the input climate fields. To assess the sensitivity to this parameter, we vary the $P D D F s$ by a value of $50 \%$ of their reference values. Changes of this order are considered to bound the physical uncertainty on these parameters [Braithwaite, 1995]. We also examine the sensitivity to changes in the standard deviation $\sigma$ by a value of $\pm 10 \%$.

[45] The results for ice volume are shown in Figure $8 \mathrm{~b}$. They show that for our choice of parameter ranges the standard deviation of daily temperatures is a less sensitive 

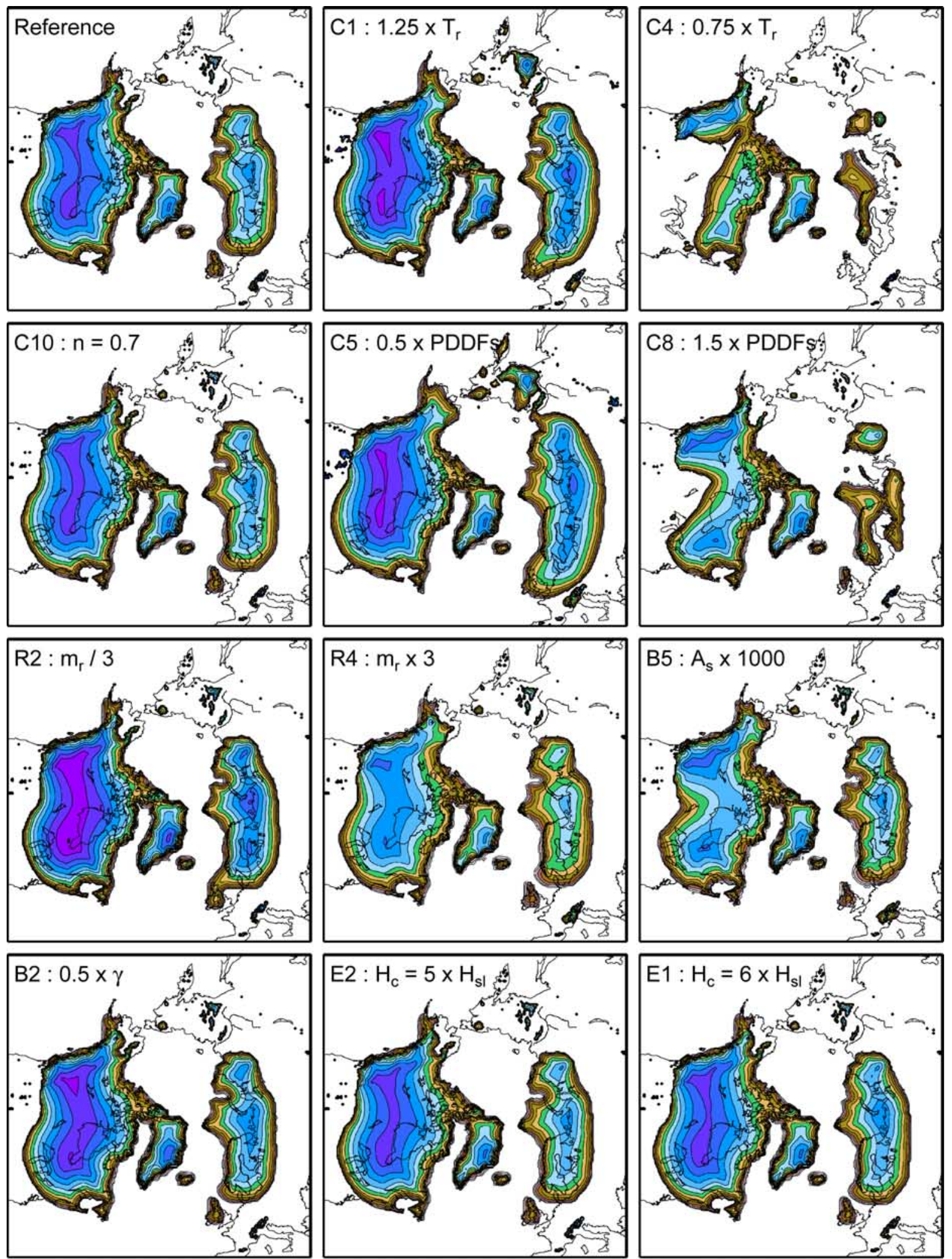

025050075010001250150017502000225025002750300032503500

Figure 9. Ice sheet surface elevation at $19 \mathrm{ka}$ cal BP for various model sensitivity runs described in the text. 
parameter than the PDDFs. Figure 9 (C5) shows the LGM ice sheet elevation when the $P D D F s$ are reduced by $50 \%$. The effect on the LGM ice extent is substantial and qualitatively similar to that when $T_{r}$ is increased by $25 \%$ (C1). For both of these model runs there is widespread glaciation in Alaska, eastern Siberia and an ice bridge between the British Isles and mainland Europe. A similar correlation in LGM ice extent is found when $T_{r}$ is decreased by $25 \%$ and the $P D D F s$ are increased by $50 \%$ (C4 and C8). In this case the ice sheets retreat substantially to the north. The North American ice sheet disintegrates in its two main components (Cordilleran and Laurentide) and the Fennoscandian ice sheet is confined to the Norwegian mountains, the Barents Sea and the Putorana mountains in northern Siberia.

[46] The similarity in volume and extent for the pairs of experiments $\mathrm{C} 5 / \mathrm{C} 1$ and $\mathrm{C} 8 / \mathrm{C} 4$ implies that variations in the $P D D F s$ and $T_{r}$ may both be used interchangeably to tune total LGM ice volume and extent to agree with the observational record. However, as the magnitudes of the PDDFs are determined by matching present day ice conditions with present day climatology, they are independent of the GCM anomalies. Assuming that the PDDFs obtained in this way are invariant under conditions of climate change, this suggests that the relationship between $T_{r}$ and the PDDFs can be used together with the ice sheet model to assess the realism of the GCM output, and moreover to determine the required magnitude of the temperature anomaly over the ice sheets. Our best results for a value of $T_{r}=1$ implies a basically correct temperature anomaly simulated by the UKMO model for the LGM. The corresponding spatially averaged temperature anomaly over all of the ice sheets obtained in this way between LGM and today is $18.5^{\circ} \mathrm{C}$.

\subsubsection{Glacial Index Exponent}

[47] The glacial index $\beta(t)^{n}$ generates interpolated states between the climate extremes of LGM and PD. With a glacial index exponent of $n=1$ a linear scaling between these two states is assumed. We focus on this assumption by varying the exponent $n$ between 0.4 and 1.6, this range being determined from experience with the model results. Choosing $n \neq 1$ will generate different interpolated climates during the glacial cycle, but conserves the climate anomalies for the end members. A value of $n>1$ biases the time dependent forcing over a glacial cycle so that the overall climate resembles more the PD climate than the LGM climate. Similarly for a value of $n<1$ the time averaged climate more resembles that of the LGM than that of the PD.

[48] The justification for this examination is three-fold. Firstly, it schematically investigates whether the $\delta^{18} \mathrm{O}$ from the GRIP ice core can be generalized over the entire northern hemisphere. For example, differences in the timing of maximum extent of the Cordilleran and Laurentide ice sheets during LGM of up to $5{ }^{14} \mathrm{C}$ ka [Dyke et al., 2002] may suggest spatial variations in climate inconsistent with atmospheric changes in the northern hemisphere which are uniform with time. Secondly, an appropriate choice of $n$ allows the modification of the shape of the resulting ice volume curve at intermediate stages between glacial and interglacial conditions. Winograd [2001] suggests that the SPECMAP benthic $\delta^{18} \mathrm{O}$ time series of Imbrie et al. [1984] does not necessarily linearly reflect global ice volume changes, and this characteristic can be controlled by an appropriate choice of $n$. Thirdly, experiments with $n>1$ may roughly deal with the effects of climate pattern shifts which occur together with migration of the ice sheet. As long as the modeled ice sheet centers have not migrated away from their inception areas, a climatic pattern more resembling the PD than the LGM may be more appropriate. This helps to avoid nucleation over the lower-lying terrain where the maximum LGM cooling is often situated at times too close to interglacial climate states.

[49] The results for ice sheet volume using different values for $n$ are shown in Figure 8c. The most significant feature is that the lower the value of $n$, the more 'sawtoothed' the pattern of ice volume growth and decay. We particularly find large differences in the net change in ice sheet volume for the period between $40 \mathrm{ka}$ cal BP and LGM. Winograd [2001] cites observational evidence which indicates that during this period northern hemisphere ice volume approximately doubled. Of the different models used here, the $n=0.7$ model $(\mathrm{C} 10)$ best matches this observation. For higher values of $n$, the volume generated over a glacial cycle is lower. That also applies to the LGM ice volume and the associated maximum surface elevations (Figure 6), though to a lesser proportion than during the intermediate moments in time. For $n=1.6$, ice volume between $40 \mathrm{ka}$ cal BP and LGM more than triples. Observations of eustatic sea level change over the last glacial cycle have trended away from the saw-toothed pattern of ice advance and retreat [e.g., Imbrie et al., 1984] to much more rapid changes in ice volume [e.g., Lambeck and Chappell, 2001]. However, as ice extent prior to the LGM is poorly constrained [Clark et al., 1993; Mangerud et al., 1998], ice sheet model predictions of eustatic sea level changes before this time should be interpreted with care.

\subsection{Rheological Processes}

[50] Of the parameters relating to ice sheet rheology, the most poorly constrained relate to the exact form of the flow law, the flow enhancement factor $m_{r}$. Here we examine the sensitivity to changes of the rate factor.

[51] We varied $m_{r}$ over a range of between 7 times less and 5 times more the value of the reference model. The lower bound corresponds to the value needed to correctly simulate the thickness of the Greenland ice sheet whereas the upper bound comes from experience with the ice sheet model. $m_{r}$ is stepped logarithmically. Figure $8 \mathrm{~d}$ shows the evolution of ice sheet volume with modifications to the rate factor. The main effect is a rescaling of the ice volume by about $15 \%$ either way for a 3 -fold change of the rate factor. This hardly affects the LGM surface area of the ice sheets as evident from Figure 9 (R2 and R4). The main impact of changes in $m_{r}$ are therefore changes in the mean thickness of the ice sheets. As noted before, the PD ice volume and maximum surface elevation of the Greenland ice sheet are underestimated by the standard model with $m_{r}=1$. Using the Greenland flow enhancement factor corresponding to $m_{r}=0.15$ the LGM ice sheet volume of the northern hemisphere ice sheets is $75 \times 10^{6} \mathrm{~km}^{3}$, or $154 \mathrm{~m}$ (corrected) of equivalent eustatic sea level change. This value is well beyond the constraints of LGM ice sheet volume using eustatic sea level maxima, but it is the only run which predicts the maximum elevation of present day 
Greenland realistically. This incompatibility has been noted before, and potential causes relating to variations in basal sliding or sediment deformation, time dependent changes in the viscosity of ice, and more detailed rheologies have been suggested [Fisher et al., 1985; Huybrechts and T'siobbel, 1997; Peltier et al., 2000; Tarasov and Peltier, 2000]. Section 2.1 notes that for notational convenience a factor of 100 has been absorbed into the values of $a$ given in Huybrechts [1990] from the flow enhancement $m_{r}$. Physically the implication of this necessity for rescaling could suggest missing or underrepresented processes such as the above. For example, Calov et al. [2002] find that the inclusion of soft sediment deformation provides a constraint on large ice sheet volumes by the introduction of quasi-periodic, large-scale surges of the Laurentide ice sheet. Similarly, large spatial variations in geothermal heat flux [Pollack et al., 1993] could locally increase ice temperature and enhance the basal flow of the ice sheet. In order to be able to reduce the flow rate enhancement factor by two orders of magnitude large changes or a combination of these processes are most likely required.

\subsection{Basal Processes}

[52] Basal processes are thought to have the potential to be very important in the long term behavior of ice sheets [e.g., Marshall and Clark, 2002], but the model physics and magnitudes of basal processes remain only poorly understood. Recent observational data from small glaciers is helping to elucidate relevant basal processes in the flow of ice [e.g., Gudmundsson et al., 1999], but it remains unclear as to whether this can be extrapolated to continent sized ice sheets. Here we examine the role of both basal sliding and geothermal heat flux in the long term dynamics of the ice sheet model.

\subsubsection{Basal Sliding}

[53] Given the uncertainty regarding the physics of basal sliding we examine its sensitivity by logarithmically stepping the basal flow parameter $A_{s}$ over 5 orders of magnitude, while leaving the form of the basal sliding relation unaltered. An additional run considers no basal sliding at all (B1).

[54] Figure 8e shows that in general these modifications lead to only small differences in ice sheet volume from that of the reference model. The result for the model with no sliding is almost indistinguishable from the reference model. When the model is run with $A_{S}$ a factor of 100 times that of the reference model, the maximum ice volume over a glacial cycle is reduced by about $4 \%$, while an increase by 1000 times implies a volume reduction by $14 \%$. The corresponding LGM surface area reduction in the latter experiment, on the other hand, is only 2\% (Figure 9, B5). This basic distinction between volume and area changes is qualitatively similar to changes in the rate factor, but the magnitude of the variations indicates a negligible role for basal flow in the reference model. To affect the ice sheet model significantly the value of $A_{s}$ should be increased by between 100 and 1000 times. Although the magnitude of basal motion is difficult to quantify, the main reason is that a large part of the base is frozen to bedrock with warm based conditions occurring only at the edges of the ice sheets (Figure 7). Consequently sliding appears to be of relatively minor importance in the overall dynamics of the northern hemisphere ice sheets considered here, although it should be noted, however, that the inclusion of basal hydraulics and the deformation of wet sediments underlying the ice sheet might make the model more sensitive to basal sliding processes than established here, suggesting that closer investigation of the glaciological consequences of these other basal processes is warranted.

\subsubsection{Geothermal Heat Flux}

[55] We modify the geothermal heat flux $\gamma$ from $21 \mathrm{~mW}$ $\mathrm{m}^{-2}$ to $63 \mathrm{~mW} \mathrm{~m}^{-2}$. This approximately covers the range observed in any region occupied by the northern hemisphere ice sheets [Blackwell and Steele, 1992; Kukkonen and Joeleht, 2003]. The role of the geothermal heat flux is to modify the heat input at the ice sheet base, which affects temperature in the basal shear layers and at the bedrock, thereby influencing the extent of basal melting and the flow rate factor. Figure 8e shows that the largest increase in LGM ice sheet volume occurs when the geothermal heat flux is reduced to half of the value of the reference model (experiment B2). That makes the ice sheet base coldest and basal sliding least widespread. For this model run the LGM ice sheet volume is about $2.5 \times 10^{6} \mathrm{~km}^{3}$ larger, but surface area hardly varies $(0.4 \%$ smaller, Figure 9$)$. This behavior in which primarily ice sheet thickness is affected is qualitatively similar to the effects of the flow enhancement factor and basal sliding.

\subsection{Glacio-Isostatic Processes}

[56] The process of glacio-isostatic adjustment is in the model controlled by two parameters. The lithospheric rigidity $D$ is related to the bending characteristics of the Earth's crust, and proportional to the cube of an 'effective elastic lithospheric thickness'. The decay time of isostatic adjustment $\tau$ is related to the viscosity of the mantle. For viscous flow in a half space $\tau$ is directly proportional to mantle viscosity, but this dependence is only conserved in sign (i.e., larger $\tau=$ more viscous mantle) for the simple model adopted here, because it has no wavelength dependence.

\subsubsection{Asthenospheric Decay Timescale}

[57] The sensitivity of the ice sheet model to changes in $\tau$ is examined over its full possible range of values, from instantaneous isostatic adjustment $(\tau=0 \mathrm{ka})$ to no adjustment at all ( $\tau$ infinite). This range goes well beyond the range of physically realistic values inferred from field observations, but highlights the total effect of including isostasy in a glaciological model. As demonstrated in Figure $8 \mathrm{f}$, over the range of values of $\tau$ from 0 to $10 \mathrm{ka}$ the ice volumes are nearly similar to those of the reference model. In general, the larger the value of $\tau$ the greater the ice volume at LGM, although for a physically meaningful range of $\tau$ the differences are small at about $1-2 \%$ of ice volume and surface area. However, when the model is run without glacial isostasy (experiment I4) the ice volume diverges dramatically with much higher values between $60 \mathrm{ka}$ cal BP and present day, together with a glacial retreat that is delayed several thousand years in time. Although for physically realistic values of $\tau$ the ice sheet model has only a small sensitivity, the inclusion of glacial isostasy does play a strong role in the evolution of the ice sheets. That is because of its control on surface elevation and thus 
on surface temperature. When the bedrock does not sink when the ice sheets grow, less marginal ablation results. In contrast to other parameters, $\tau$ also significantly influences the timing of maximum LGM ice volume. The no isostasy model (I4) reaches its LGM maximum at $18.9 \mathrm{ka}$ cal BP, about 900 years earlier than that of the instantaneous isostasy model (I1). The greater the value of $\tau$ the earlier the deglaciation begins. The process of glacial isostasy therefore slows the advance of ice and speeds up its retreat. This is in accord with earlier work of a more schematic nature [Oerlemans and van der Veen, 1984], although using a more sophisticated climate model Crucifix et al. [2001] find that a simple ice sheet model with glacial isostasy generates a faster deglaciation of the ice sheets than a simulation in which isostasy is absent.

\subsubsection{Rigidity of the Lithosphere}

[58] The investigated range of $D$ of between $10^{24} \mathrm{Nm}$ (experiment I6) and $10^{25} \mathrm{Nm}$ (reference model) represents the range of geophysically realistic values for the effective thickness of the lithosphere [e.g., Lambeck et al., 1998; Milne et al., 2001], which using the formulation of Cathles [1975] are $50 \mathrm{~km}$ and $105 \mathrm{~km}$ respectively. The resulting differences in ice sheet evolution are, however, minor, as shown in Figure $8 \mathrm{~g}$. The extreme case with $D=0 \mathrm{Nm}$ (experiment I5), equivalent to local glacio-isostatic compensation, only generates $6 \%$ more ice than that of the reference model at the LGM. The main reason is the higher surface elevation at the margin (and thus lower temperature and ablation) as there is no deflection component at the periphery from the much thicker ice in the ice sheet interior. As $10^{25} \mathrm{Nm}$ generally represents an upper bound in the thickness of the lithosphere, the difference in ice volume between I6 and the reference model of $1.4 \times 10^{6} \mathrm{~km}^{3}$, or about $2.5 \%$, should be considered to represent the total sensitivity of the ice sheet model to the rigidity of the lithosphere.

\subsection{Marine Extent Parameterization}

[59] The marine extent parameterization is sensitive to the climate and rheological formulation of the ice sheet model, as these control the thickness of the ice sheets over the marine margin, which together with the hydro-isostatic formulation modify the depth of marine bathymetry. The formulation generates complete calving at locations where the marine bathymetry is deeper than $H_{c}$ (equation (12)). The marine extent of the ice sheets is directly dependent on the prescribed eustatic sea level change and indirectly dependent on changes in the bathymetry of the marine margin. Therefore changes to many components of the ice sheet model require modification of the details of the marine extent parameterization to realistically reproduce the geomorphological observations. The standard marine extent relationship is a hybrid equation (separated at $\Delta H_{s l}=$ $-80 \mathrm{~m}$ ) with different gradients for different segments of eustatic sea level change. For the reference model the maximum bathymetric depth occurs at $21 \mathrm{ka}$ cal BP and is $713 \mathrm{~m}$ below present-day sea level. Here we explore the sensitivity of the model to simple linear variants of equation (12), designed to generate maximum ice sheet extents at bathymetries of between $-520 \mathrm{~m}$ and $-780 \mathrm{~m}$. We substitute the maximum bathymetric depth for calving $H_{c}$ to $6 \times \Delta H_{s l}$ (maximum $780 \mathrm{~m}$ bathymetry, experi- ment E1) and $4 \times \Delta H_{s l}$ (maximum $520 \mathrm{~m}$ bathymetry, experiment E3). These extremes in the formulations for $H_{c}$ are chosen to represent physically reasonable limits on $H_{c}$. To examine the role of hybridization in equation (12), we also outline the results of a model with close resemblance to that of the reference model, where $H_{c}=$ $5 \times \Delta H_{s l}$ (maximum $650 \mathrm{~m}$ bathymetry, experiment E2). [60] Figure $8 \mathrm{~h}$ shows the resulting time-dependent changes in total ice volume generated over the last glacial cycle. The LGM ice volume of the $H_{c}=5 \times \Delta H_{s l}$ model run (E2) is very similar to the reference run. The other two experiments with different maximum bathymetric depths diverge more substantially as the LGM ice sheets expand to different limits. However, all models show major differences in the timing and magnitude of ice volume change, particularly in the retreat of the ice sheets after the LGM. The maximum difference in timing is almost $1 \mathrm{ka}$ at LGM but increases to $5 \mathrm{ka}$ during the glacial-interglacial retreat. Figure 9 (E2) shows the LGM ice sheet elevation of the model which most closely resembles the reference model. Although quite similar in surface elevation to that of the reference model, the St Anna Trough (Figure 1) is ice free at LGM for the E2 model, contrary to the geomorphological evidence [Polyak et al., 1997] and the reference experiment. The St Anna Trough has the deepest marine bathymetry of any region of the continental shelves of the northern hemisphere over which glaciation is thought to have taken place, but its grounding cannot be simulated by the $H_{c}=$ $5 \times \Delta H_{s l}$ model. Therefore a simple linear relationship is insufficient to correctly reproduce the observed marine infiltration of the northern hemisphere ice sheets. The E1 model run predicts a glaciated St Anna Trough at LGM (Figure 9), but the timing of retreat of the marine based ice for this model is inconsistent with the observations. In particular Hudson Bay is deglaciated at $11 \mathrm{ka}$ cal BP, inconsistent with the observed timing of $9 \mathrm{ka}$ cal BP [Dyke and Prest, 1987]. The $4 \times \Delta H_{s l}$ run (E3), on the other hand, predicts that at LGM a major area of the Barents Sea and Hudson Bay was ice free (not shown). The results for these models outline why the marine extent parameterization has its hybrid form. Otherwise there is a basic inconsistency in the timing and extent of ice sheets over the continental shelves. Zweck and Huybrechts [2003] suggest that the hybridization in equation (12) is a result of a requirement to prescribe separate fast and slow calving processes, which could be related to a dependence on the magnitude of marine calving being determined in part by whether the ice is floating or grounded [e.g., Vieli et al., 2001].

\section{Hierarchy of Model Parameters}

\subsection{Method}

[61] In the preceding section the sensitivity of the ice sheet model to model parameters was outlined in a qualitative manner, but this provides only anecdotal insight as to the relative importance of individual parameters. A more quantitative approach that is able to produce a parameter ranking is therefore desirable. For that purpose, model parameters were systematically stepped over their entire ranges of uncertainty and model output examined. The step size was chosen to linearly span the respective parameter ranges in 20 equal parts. Where the range of uncertainty 

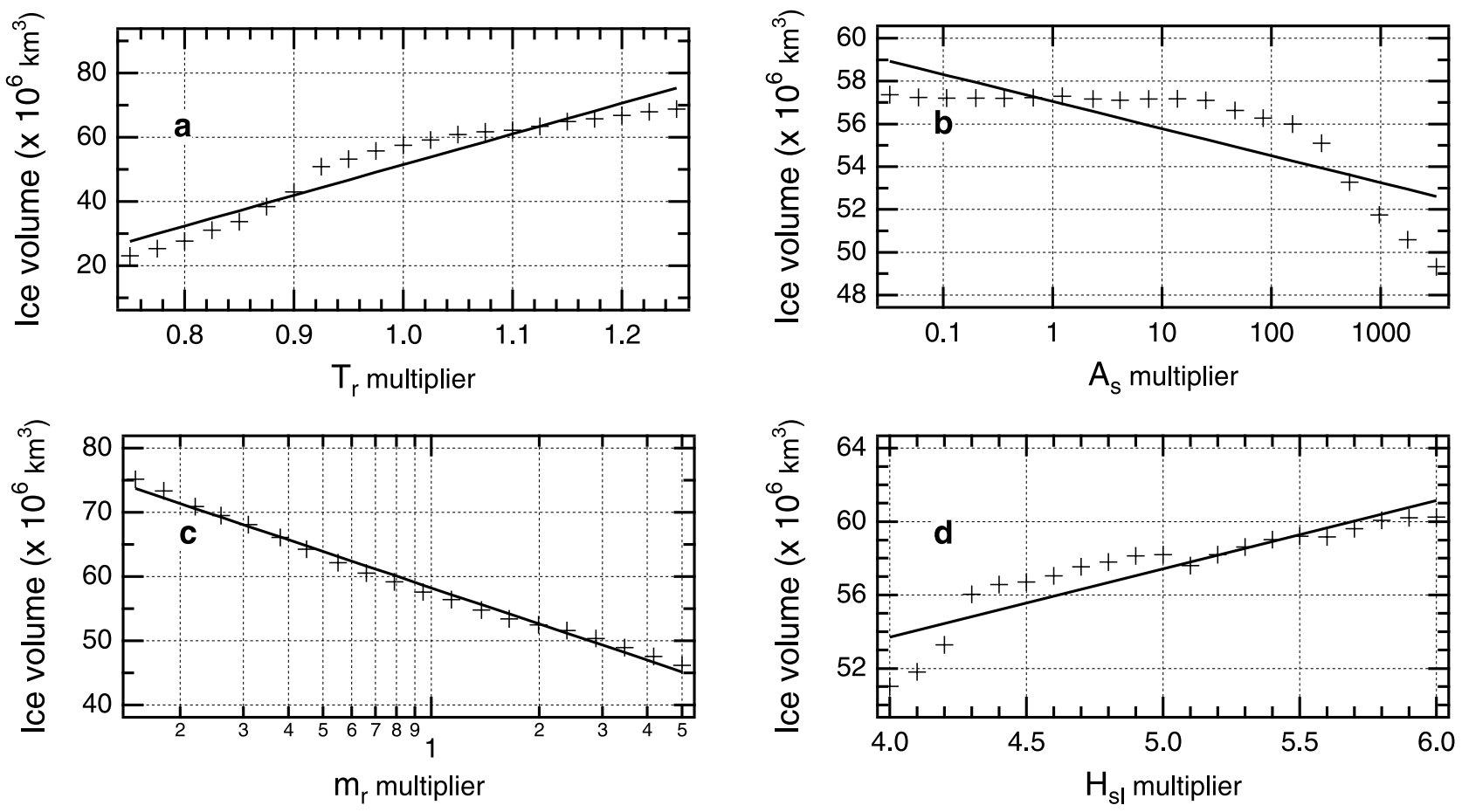

Figure 10. Examples of the sensitivity of Last Glacial Maximum (LGM) ice volume to changes in model parameters charted over the model parameter space. Symbols show the LGM ice volume determined by the ice sheet model; lines show the interpolated linear fit. (a) Sensitivity of total ice volume to changes in $T_{r}$, the input temperature difference between LGM and present day. (b) Sensitivity to the sliding parameter $A_{s}$. (c) Sensitivity to the flow enhancement $m_{r}$. (d) Sensitivity to $H_{c}$ the marine calving formulation.

occurs over an order of magnitude or where the parameter under investigation is an internal multiplier in the ice dynamical model (flow enhancement, sliding, decay time), values were chosen to span the decadal parameter space using a logarithmic scale. Since differences in model results generally scale well during a glacial cycle (Figure 8), only the model outputs of maximum LGM ice volume, surface area, mean thickness, and timing were examined.

[62] Next, the results for each parameter were generalized over their entire range of uncertainty by a linear leastsquares best fit. The degree to which this is meaningful is given by the associated cross-correlation coefficient. Figure 10 shows selected examples of this procedure, illustrating how the modeled maximum LGM ice sheet volume varies over the range of parameter uncertainty for the parameters involving the UKMO temperature multiplier $T_{r}$ (Figure 10a), the sliding enhancement factor $A_{S}$ (Figure 10b), the flow enhancement factor $m_{r}$ (Figure 10c), and the bathymetric depth in the marine calving parameterization $H_{c}$ (Figure 10d). For these examples, the method works best for the multiplier in the flow law $m_{r}\left(\mathrm{R}^{2}=\right.$ 0.99), but also brought to light asymmetries in some of the model responses. For example, Figure 10b shows that sliding only plays a strong role in the determination of LGM ice sheet volume for values beyond $50 \times A_{s}$. The results obtained from the various model tests are summarized in Table 2. It should be noted that the linearization conducted here is not designed to determine how well the results can be interpolated over the entire parameter space of the model, but simply to examine the extent to which the results of the previous section can be generalised to establish a hierarchy of importance of model parameters. Charbit et al. [2002] find that simultaneously changing basal sliding, precipitation and GRIP forcing has the same effect of the sum of individually changing the parameters (i.e., no non-linear amplification of response) but this is unlikely to be the case for all model parameters.

[63] In order to produce the parameter hierarchy we use the slopes of the linear fits obtained over the entire parameter space. A usable quantitative measure of parameter importance is provided by the model response to a $10 \%$ change in that parameter value, similar in approach to the estimates of climate sensitivity to a doubling of $\mathrm{CO}_{2}$ based on transient model runs of atmospheric GCMs [e.g., Stouffer and Manabe, 1999; Gregory et al., 2004]. This, however, introduces a certain amount of arbitrariness as each model parameter plays a different role and behaves in a different way. This applies in particular to the internal multipliers in the ice-dynamics model that were stepped logarithmically. Therefore a second measure of parameter importance is provided by the range of the model response over the total range of the parameter variation. This effectively normalizes the response to each parameter over their ranges of uncertainty. The latter ranges have been chosen either through the physical uncertainty on each model parameter as established by field observations or laboratory studies, or through experience with the ice sheet model as representing physically realistic bounds for the ice sheet dynamics. As it is difficult to prefer one ranking method above another, the outcomes of both methods are shown 

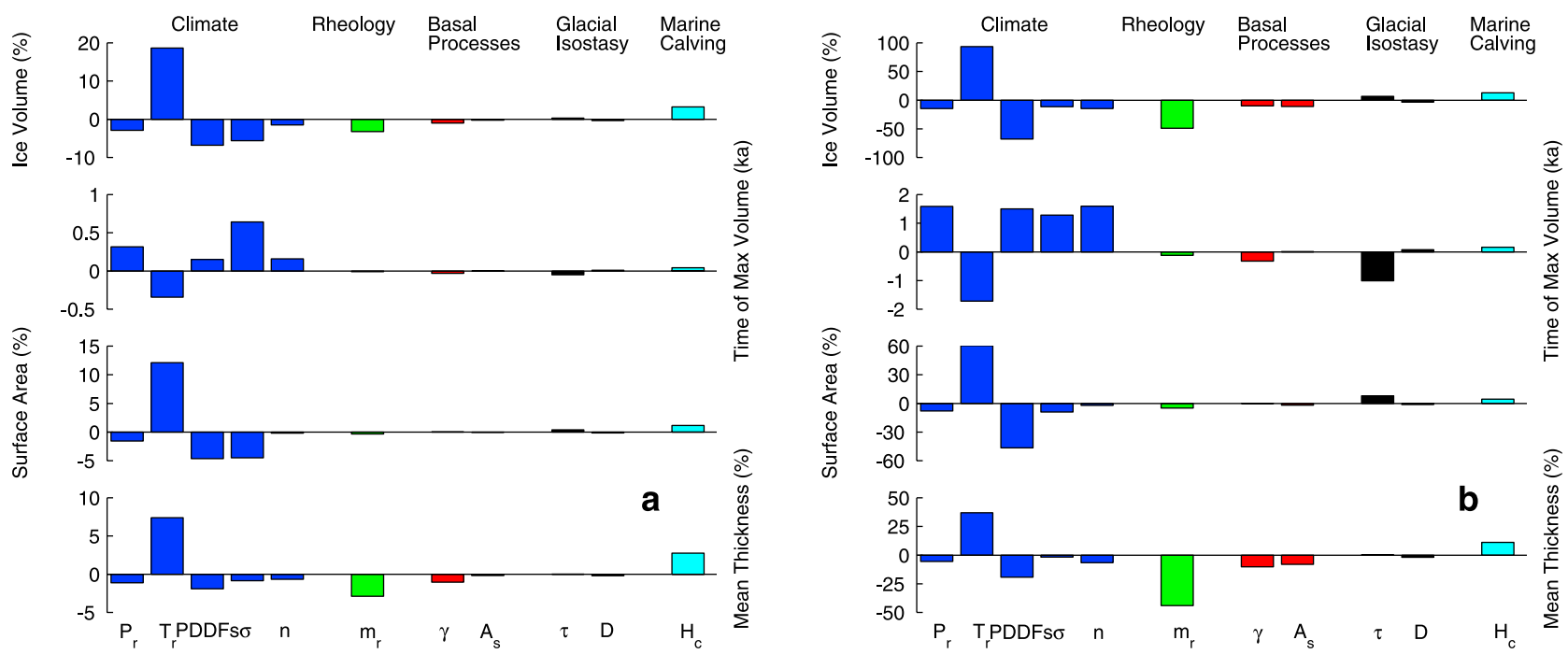

Figure 11. Overall model sensitivity of the model output to changes in the value of the parameters of the reference model. Model outputs are maximum ice volume, the time difference at which the ice volume is a maximum, maximum surface area and maximum mean ice thickness. (a) Sensitivity to a $10 \%$ change in model parameter. (b) Sensitivity for the total range over which the respective model parameter was investigated. The sign of each sensitivity is given by the correlation of the parameter with the model output.

together in Table 2 and in Figure 11. However, as can be seen, the general features obtained in both ways are quite similar.

[64] There are two major advantages of this method over either a subsampling of parameter space [e.g., Bintanja et al., 2002; Charbit et al., 2002] or an ensemble analysis [e.g., Marshall et al., 2002; Tarasov and Peltier, 2004]. The first is that the specific magnitude of effect on the ice sheet model when changes to each model parameter are made can be quantified, so that processes responsible for differences between the reference model and the observational record can be identified. In this manner the results presented here are not applicable just to the current state of the observational record, but can be generalized to findings resulting from future improvements and reevaluations in the observational record (for example differences between ICE-5G and ICE-4G can be determined as a function of the sliding parameter $A_{s}$, and differences in Fennoscandian ice extent over the Kara Sea can be determined as a function of the climate forcing imprinting in $T_{r}$ ). The second is that via a thorough sampling of parameter space the relative importance of each model parameter can be listed in terms of glaciologically relevant model output, so that the dominance of each parameter and the degree of parameter space trading within the ice sheet model can be quantified.

\subsection{Sensitivity of Maximum LGM Ice Volume}

[65] Figure 11 clearly shows that the parameters which control the climatic input exert the strongest influence on LGM ice sheet volume. The model is most sensitive to the temperature rescaling factor and the positive degree day factors $(P D D F S)$. Both parameters directly affect ablation. They also behave quite regularly as evident from their correlation coefficients $\mathrm{R}^{2}$ of 0.92 and 0.99 respectively. A second dominant control is ice rheology as represented by the flow enhancement factor $m_{r}$, but as this parameter scales logarithmically, this becomes only clear when the entire realistic parameter range is considered. Geothermal heat flux $\gamma$ correlates best with maximum LGM ice volume $\left(\mathrm{R}^{2}=1.00\right)$ but has only a small role in terms of absolute changes in ice volume (10\% over total parameter range). Maximum LGM ice volume is an important model output to compare with observations of the amplitude of eustatic sea level change. Figure 11 shows that both the strength of the ablation and the softness of the ice can be used interchangeably for tuning purposes. The least-well correlated model parameter with LGM ice sheet volume is $A_{s}$, the parameter controlling sliding $\left(\mathrm{R}^{2}=0.61\right)$. Figure $10 \mathrm{~b}$ shows that this is due to an asymmetry of sensitivity of LGM ice volume around the reference value of the parameter space of $A_{s}$. However, Table 2 and Figure 11 also demonstrate that the maximum ice volume is relatively insensitive to $A_{s}$, and a similar remark applies to the process of glacial isostasy.

\subsection{Sensitivity of Timing of Maximum LGM Ice Volume}

[66] Table 2 shows that there is a large scatter in the timing of maximum ice volume on the northern hemisphere ice sheets. The strongest controls are climate and to a lesser extent glacial isostasy, particularly the decay time of adjustment $\tau$, though glacial isostasy is not the dominant control (Figure 11). Further inspection of individual model results suggests that the latter sensitivity mainly operates through hydro-isostatically induced changes of marine topography and its role in the calving parameterization. The earliest maximum occurs for the $\mathrm{C} 1$ model, with $1.25 \times T_{r}$. This is also the model which generates the greatest ice volume at maximum, with $19 \%$ more ice than that of the reference model. The latest ice volume maximum occurs for the $\mathrm{C} 2$ model, with $1.25 \times P_{r}$, underscoring the dominant role of the input climate fields. That is because the onset of retreat of the ice sheets occurs only after the time when ablation at 
the margin becomes sufficiently large, which is most strongly controlled by the input climate. Inspection of Table 2 shows that $\sigma$ and $n$ also play an important role in this timing, also due to their effect on mass balance. Of special note are the comparably low sensitivities to the rheology and sliding of the ice sheets, as well as the lack of any significant correlation. This suggests that the onset of the retreat of the northern hemisphere ice sheets is driven predominantly by climate changes, rather than by internal feedbacks related to mass flux imbalances caused by transient features in the dynamics of the ice sheets.

\subsection{Sensitivity of Maximum LGM Surface Area}

[67] The maximum surface area of the LGM ice sheets distinguishes itself from the other output parameters in that it is almost solely controlled by the surface climate. The two most sensitive model parameters are $T_{r}$ and the PDDFs, which both control the amount of ablation at the margin and therefore the ice sheet extent. For the reference model, the maximum in surface area occurs at $21.6 \mathrm{ka}$ cal BP, about $3 \mathrm{ka}$ earlier than the maximum in volume. This is consistent with the notion of a time lag with which the overall ice sheet responds to changes at the margin. The modeled ice sheet extent can be compared with the geomorphological observations (e.g., Figure 1), with the analysis here reinforcing the observation in Section 4.1.2 that with the PDDFs chosen to simulate PD conditions $T_{r}$ can be modified so that the model closely reproduces the geomorphological observations. However, as the geomorphological observations are only dated to within a few thousand years [Dyke et al., 2002; Svendsen et al., 1999], the phase lag between maximum surface area and maximum volume of the ice sheets provides only a weak constraint on the variation in ice sheet dynamics resulting from the imposed climate changes. The relatively low sensitivity of the maximum modeled LGM surface area of the ice sheets to basal and glacial-isostatic adjustment processes suggests that they only modify the dynamics of existing ice (Figure 11 and Table 2) and do not promote advances and retreats of the ice sheets over large distances. The low sensitivity of modeled ice sheet surface area to the marine calving parameterization also reflects that the area of marine grounded ice during the LGM was only a small fraction of the total ice extent of the northern hemisphere ice sheets.

\subsection{Sensitivity of Maximum LGM Mean Ice Sheet Thickness}

[68] For the reference model, the maximum in LGM mean ice sheet thickness is $2114 \mathrm{~m}$ and occurs at $17.1 \mathrm{ka}$ cal BP, about $1 \mathrm{ka}$ later than the maximum in ice sheet volume but $4 \mathrm{ka}$ later than the maximum in surface area. This timing reflects how a climatic warming first causes retreat of the margin, after which a thinning wave travels upstream because of the larger surface slopes, to ultimately thin central areas with a time lag of several thousand years. Figure 11 shows that for all model parameters considered here the flow enhancement factor $m_{r}$ exerts the strongest control on the maximum LGM mean thickness. Table 2 further shows that apart from geothermal heat flux $m_{r}$ is also the most strongly correlated with mean thickness, presumably due to its spatial and temporal uniformity in the model.

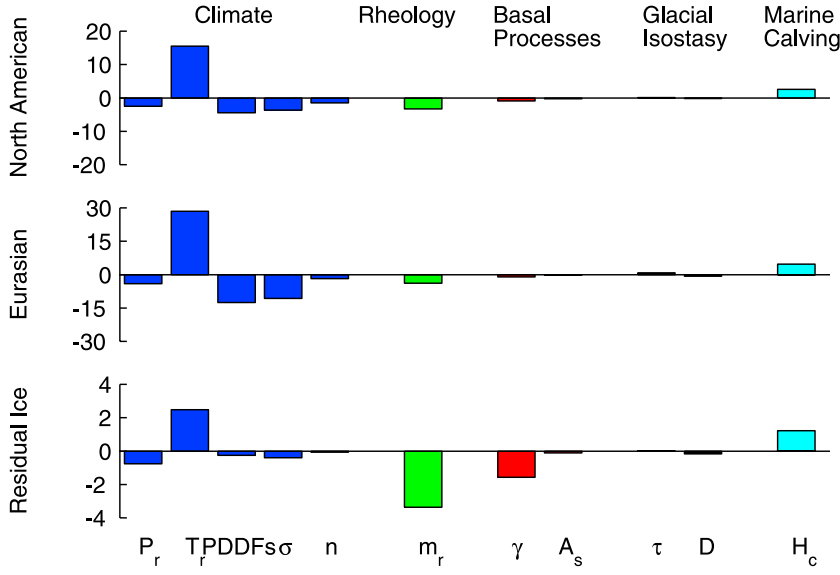

Figure 12. Sensitivity of maximum Last Glacial Maximum ice sheet volume to a $10 \%$ increase in model parameter shown for individual ice sheets. The residual ice is mainly on Greenland, but also includes Iceland. The sign of each sensitivity is given by the correlation of the parameter with the model output.

The dominant role of $m_{r}$ on ice thickness is in strong contrast to its negligible control on surface area. Apparently the hardness of the ice almost exclusively controls the local ice thickness but has little influence on the lateral extent of the ice sheets. In other words, the viscosity of the ice controls the speed at which, and hence, the ice depth over which, a certain ice flux is transported, but the flux itself is determined by the surface mass balance, and so is lateral extent. A similar role, albeit less dominant, is played by the parameters related to basal processes $\left(\gamma\right.$ and $\left.A_{s}\right)$. The parameter least correlated with maximum LGM mean ice sheet thickness is $\tau$.

\subsection{Sensitivity of Maximum LGM Ice Volume for Individual Ice Sheets}

[69] In order to see the relative effects of model parameters on individual ice sheets, Figure 12 presents the results of a $10 \%$ parameter change on maximum LGM ice volume but for each ice sheet complex separately. Of particular note is the similarity in the hierarchy of important model parameters for the North American and Eurasian ice sheets. For both of these ice sheets climate processes dominate. This is very similar to the overall behavior shown in Figure 11a (upper bar) as both ice sheets represent 91\% of the total sensitivity (North American: 58\%, Eurasian: 33\%). However, for the remaining ice sheets, mainly the Greenland ice sheet, the flow enhancement $m_{r}$ is more important than climate processes. The reason for this differential behavior is that the Greenland and Iceland ice sheets are situated on islands in a more polar setting than the North American and Eurasian ice sheets. Because of that they reach the marine limits on their areal extent rather early during the glaciation, beyond which stage surface melt is no longer able to control ice volume by means of variations in ice sheet extent.

\section{Conclusions}

[70] In this paper we have simulated the northern hemisphere ice sheets during the last glacial cycle with a new 
ice-dynamic model, improved from earlier work with better mass balance parameterizations, a more sophisticated treatment of glacial isostasy, the inclusion of marine calving, and a climatic forcing derived from palaeo time slice experiments with the UKMO General Circulation Model. Model output was evaluated on the basis of a best fit with present-day ice cover, inferred maximum Last Glacial Maximum extent, and constraints on the total global eustatic sea level lowering. We generally find a reasonably good agreement between the model and the geological record to within the limits of the climate forcing. The main mismatch is the simulation of excessive ice over the Taimyr Peninsula. This is attributed to defects in the ICE-4G ice sheet configuration which was originally embedded in the Paleoclimate Model Intercomparison Project climate simulations. Another remarkable feature of the simulations concerned the thinness of the present day Greenland ice sheet when using rheological parameters tuned to the Last Glacial Maximum ice sheets, but no clear explanation for this apparent paradox could be given. In our standard simulation, we find a maximum Last Glacial Maximum eustatic sea level lowering of $110 \mathrm{~m}$ at $18.5 \mathrm{ka}$ cal BP, of which $82.1 \mathrm{~m}$ resulted from the North American ice sheet, $25.4 \mathrm{~m}$ from the Eurasian ice sheet and $2.1 \mathrm{~m}$ from the Greenland ice sheet.

[71] The sensitivity study brought to light the role of the different model parameters and allowed the use of the model in 'diagnostic mode' to establish a ranking of parameter importance to within their known uncertainty. The most crucial processes affecting the history of the northern hemisphere ice sheets are related to the climate and to a lesser extent to the rheology of the ice sheets. The most dominant parameter is the one controlling the temperature depression between the Last Glacial Maximum and the present day. This conclusion is perhaps the most intuitive, but allows at the same time to quantify the spatially averaged annual cooling over the ice sheets between the Last Glacial Maximum and the present day. Its value recovered here is $18.5^{\circ} \mathrm{C}$, colder than the $11^{\circ} \mathrm{C}$ recovered for the North American ice sheet by Marshall et al. [2002]. This difference could reflect differences arising from the usage of different climate physics (e.g., elevation desert effect) or from the different spatial patterns of climate fields generated by the different models used in the Paleoclimate Model Intercomparison Project. By calibrating climate forcing by comparing modeled and observed eustatic sea level change from the ice sheets, Bintanja et al. [2004] estimate a temperature difference between the Last Glacial Maximum and the present day over the continents north of $40^{\circ} \mathrm{N}$ of $8.3^{\circ} \mathrm{C}$. For the model outputs examined here, climate parameters almost exclusively control ice sheet extent, but for ice thickness the flow enhancement factor is more important, whereas the decay time for glacial isostasy and marine calving are also important for the timing of the Last Glacial Maximum. Our modeled ice sheets are least sensitive to basal processes (basal sliding, geothermal heat flux) and to the flexural rigidity of the lithosphere.

[72] An advantage of the methodology presented here is that the results are not strongly dependent on the determination of parameters of the reference model. The results show that the misfit in modeled ice extent over the Kara Sea and the Taimyr Peninsula compared to the observations recovered from the QUEEN project is a function predominantly of $T_{r}$, which controls the magnitude of climate difference imprinting. Similarly the role of basal sliding $A_{s}$ which plays a strong role in the determination of the domal structure of the ice sheets is shown here to affect Last Glacial Maximum ice volumes and thicknesses while not affecting the surface area or timing of maximum ice volumes. This is also true of the marine calving formulation, and this result is relatively independent of the details of the reference model parameters or of recent reevaluations of the observational record, for example the reinterpretation of the timing of the infiltration of the Barents Sea from $18 \mathrm{ka}$ cal BP [Landvik et al., 1998] to $14 \mathrm{ka}$ cal BP [Svendsen et al., 2004b]. Also independent of the reference model parameters are the low correlations for basal, glacial isostatic and marine calving processes which highlight the variability of the ice sheet model resulting from the spatial heterogeneity of the topography of the Earth.

[73] The separation of parameter effects can be well exploited to infer the value of the more sensitive model parameters for a given climate forcing. The technique is to first determine the value of $P D D F S$ and $\sigma$ from a steady state, present day simulation. Next, the strength of the anomaly climate fields can be adjusted in glacial cycle simulations until the Last Glacial Maximum surface area of the ice sheets matches the geomorphological observations. Thirdly, the flow enhancement factor is tuned until the modeled Last Glacial Maximum ice volume is consistent with observations of eustatic sea level change. Finally, the marine calving parameterization is modified until the retreat of marine grounded ice is reproduced realistically.

[74] An obvious future direction of research is using internally consistent coupled climate/ice sheet models to reproduce the geomorphological observations without having to introduce the a priori signature of the Last Glacial Maximum ice sheets as was done here. Another improvement is to vary free model parameters among the different ice sheet complexes of the northern hemisphere. We expect the parameter sensitivity study as performed here to be a good guide to obtain better reconstructions in such further work.

[75] Acknowledgments. This work was performed within the HGF-Strategiefonds Projekt 2000/13 SEAL (Sea Level Change). We especially thank Chris Hewitt, Jonathan Gregory, and Guy Munhoven for their help in obtaining and processing the UKMO PMIP climate fields over our model domain. Three anonymous reviewers provided constructive comments that improved the manuscript significantly.

\section{References}

Alley, R. B., P. A. Mayewski, T. Sowers, M. Stuiver, K. C. Taylor, and P. U. Clark (1997), Holocene climatic instability: A prominent, widespread event 8200 yr ago, Geology, 25(6), 483-486.

Bard, E., B. Hamelin, M. Arnold, L. Montaggioni, G. Cabioch, G. Faure, and F. Rougerie (1996), Deglacial sea-level record from Tahiti corals and the timing of global meltwater discharge, Nature, 241-244, 382.

Bintanja, R., R. S. W. van de Wal, and J. Oerlemans (2002), Global ice volume variations through the last glacial cycle simulated by a 3-D icedynamical model, Quat. Int., 11-23, 95-96.

Bintanja, R., R. S. W. van de Wal, and J. Oerlemans (2004), A new method to estimate ice age temperatures, Clim. Dyn., doi:10.1007/s00382-0040486-X.

Blackwell, D. D., and J. L. Steele (1992), Geothermal map of North America, map scale 1:5,000,000, Geol. Soc. of Am., Boulder, Colo. 
Bowen, D. Q., F. M. Phillips, A. M. McCabe, P. C. Knutz, and G. A. Sykes (2002), New data for the Last Glacial Maximum in Great Britain and Ireland, Quat. Sci. Rev., 21, 89-101.

Braithwaite, R. J. (1995), Positive degree-day factors for ablation on the Greenland ice sheet studied by energy-balance modeling, J. Glaciol., 41(137), $153-160$.

Calov, R., A. Ganopolski, V. Petoukhov, and M. Claussen (2002), Largescale instabilities of the Laurentide ice sheet simulated in a fully coupled climate-system model, Geophys. Res. Lett., 29(24), 2216, doi:10.1029/ 2002GL016078.

Cathles, L. M. (1975), The Viscosity of the Earth's Mantle, Princeton Univ. Press, Princeton, N. J.

Charbit, S., C. Ritz, and G. Ramstein (2002), Simulations of Northern Hemisphere ice-sheet retreat: Sensitivity to physical mechanisms involved during the Last Deglaciation, Quat. Sci. Rev., 21, 243-265.

Clark, P. U. (1994), Unstable behavior of the Laurentide ice sheet over deforming sediment and its implications for climate change, Quat. Res., 41, 19-25.

Clark, P. U., and A. C. Mix (2002), Ice sheets and sea level of the Last Glacial Maximum, Quat. Sci. Rev., 21, 1-7.

Clark, P. U., et al. (1993), Initiation and development of the Laurentide and Cordilleran Ice Sheets following the last interglaciation, Quat. Sci. Rev., $12,79-114$

Clark, P. U., J. X. Mitrovica, G. A. Milne, and M. E. Tamisiea (2002), Sealevel fingerprinting as a direct test for the source of global meltwater pulse 1A, Science, 295, 2438-2441.

Crucifix, M., and M. F. Loutre (2002), Transient simulations over the last interglacial period (126-115 kyr BP): Feedback and forcing analysis, Clim. Dyn., 19, 417-433.

Crucifix, M., M. F. Loutre, K. Lambeck, and A. Berger (2001), Effect of isostatic rebound on modeled ice volume variations during the last 200 kyr, Earth Planet. Sci. Lett., 184, 623-633.

Dansgaard, W., et al. (1993), Evidence for general instability of past climate from a 250-kyr ice-core record, Nature, 364, 218-220.

Denton, G. H., and T. J. Hughes (2002), Reconstructing the Antarctic Ice Sheet at the Last Glacial Maximum, Quat. Sci. Rev., 21, 193-202.

Dyke, A. S., and V. K. Prest (1987), Late Wisconsinan and Holocene retreat of the Laurentide ice sheet, Map 1702A, scale 1:5,000,000, Geol. Surv. of Can., Ottawa, Ont.

Dyke, A. S., J. S. Vincent, J. T. Andrews, L. A. Dredge, and W. R. Cowan (1989), The Laurentide ice sheet and an introduction to the Quaternary geology of the Canadian Shield, in Ouaternary Geology of Canada and Greenland, edited by R. J. Fulton, pp. 178-317, Geol. Surv. of Can., Ottawa, Ont.

Dyke, A. S., J. T. Andrews, P. U. Clark, J. H. England, G. H. Miller, J. Shaw, and J. J. Veillette (2002), The Laurentide and Innuitian ice sheets during the Last Glacial Maximum, Quat. Sci. Rev., 21, 9-31.

England, J. (1999), Coalescent Greenland and Innuitian ice during the Last Glacial Maximum: Revising the Quaternary of the Canadian High Arctic, Quat. Sci. Rev., 18, 421-456.

Fairbanks, R. G. (1989), A 17,000-year glacio-eustatic sea level record Influence of glacial melting rates on the Younger Dryas event and deep-ocean circulation, Nature, 342, 637-642.

Fisher, D. A., N. Reeh, and K. Langley (1985), Objective reconstructions of the late Wisconsinan Laurentide Ice Sheet and the significance of deformable beds, Geogr. Phys. Quat., 39, 229-238.

Forsström, P.-L., and R. Greve (2004), Simulation of the Eurasian ice sheet dynamics during the last glaciation, Global Planet. Change, 42(1-4), $59-81$.

Gregory, J. M., W. J. Ingram, M. A. Palmer, G. S. Jones, P. A. Scott, R. B. Thorpe, J. A. Lowe, T. C. Johns, and K. D. Williams (2004), A new method for diagnosing radiative forcing and climate sensitivity, Geophys. Res. Lett., 31, L03205, doi:10.1029/2003GL018747.

Greve, R., K. H. Wyrwoll, and A. Eisenhauer (1999), Deglaciation of the Northern Hemisphere at the onset of the Eemian and Holocene, Ann. Glaciol., 28, 1-8.

Grosswald, M. G. (1993), Extent and melting history of the Late Weichselian ice sheet, the Barents-Kara continental margin, in Ice in the Climate System, NATO ASI Ser., vol. I12, edited by W. R. Peltier, pp. 1-20, Springer, New York.

Gudmundsson, G. H., A. Bauder, M. Lüthi, U. H. Fischer, and M. Funk (1999), Estimating rates of basal motion from continuous tilt measurements, Ann. Glaciol., 28, 247-252.

Hays, J. D., J. Z. Imbrie, and N. J. Shackleton (1976), Variations in the Earth's orbit: Pacemaker of the ice ages, Science, 194(4270), 1121-1132.

Hewitt, C. D., and J. F. B. Mitchell (1997), Radiative forcing and response of a GCM to ice age boundary conditions: Cloud feedback and climate sensitivity, Clim. Dyn., 13, 821-834.

Huybrechts, P. (1990), A 3-D model for the Antarctic ice sheet: A sensitivity study on the glacial-interglacial contrast, Clim. Dyn., 5, 79-92.
Huybrechts, P. (1996), Basal temperature conditions of the Greenland ice sheet during the glacial cycles, Ann. Glaciol., 23, 226-236.

Huybrechts, P. (2002), Sea-level changes at the LGM from ice-dynamic reconstructions of the Greenland and Antarctic ice sheets during glacial cycles, Quat. Sci. Rev., 21, 203-231.

Huybrechts, P., and S. T'siobbel (1995), Thermomechanical modeling of Northern Hemisphere ice sheets with a two-level mass-balance parameterization, Ann. Glaciol., 21, 111-116.

Huybrechts, P., and S. T'siobbel (1997), A three-dimensional climate-icesheet model applied to the Last Glacial Maximum, Ann. Glaciol., 25, $333-339$

Imbrie, J. Z., J. D. Hays, D. G. Martinson, A. MacIntyre, A. C. Mix, J. J. Morley, N. G. Pisias, W. L. Prell, and N. J. Shackleton (1984), The orbital theory of Pleistocene climate: Support from a revised chronology of the marine $\delta^{18} \mathrm{O}$ record, in Milankovitch and Climate, edited by A. Berger et al., pp. 269-305, Springer, New York.

Jaeger, L. (1976), Monatskarten des Niederschlags fur die ganze Erde, Ber. Dtsch. Wetterdienstes, 18(139), 1-38.

Janssens, I., and P. Huybrechts (2000), The treatment of meltwater retention in mass-balance parameterizations of the Greenland ice sheet, Ann. Glaciol., 31, 133-140.

Joussaume, S., and K. E. Taylor (1995), Status of the paleoclimate modeling intercomparison project (PMIP), in Proceedings of the First International AMIP Conference, edited by W. L. Gates, WCRP-92, pp. 425-430, World Meteorol. Org., Geneva.

Kageyama, M., and P. J. Valdes (2000), Impact of the North American icesheet orography on the Last Glacial Maximum eddies and snowfall, Geophys. Res. Lett., 27(10), 1515-1518.

Kalnay, E., et al. (1996), The NCEP/NCAR 40-year reanalysis project, Bull. Am. Meteorol. Soc., 77, 437-471.

Kleman, J., and C. Hättestrand (1999), Frozen-bed Fennoscandian and Laurentide ice sheets during the Last Glacial Maximum, Nature, 402, $63-66$.

Knies, J., H. P. Kleiber, J. Matthiessen, C. Muller, and N. Nowaczyk (2001), Marine ice-rafted debris records constrain maximum extent of Saalian and Weichselian ice-sheets along the northern Eurasian margin, Global Planet. Change, 31, 45-64.

Kukkonen, I. T., and A. Jõeleht (2003), Weichselian temperatures from geothermal heat flow data, J. Geophys. Res., 108(B3), 2163, doi:10.1029/2001JB001579.

Lambeck, K. (1995), Constraints on the Late Weichselian Ice Sheet over the Barents Sea from observations of raised shorelines, Quat. Sci. Rev., 14, $1-16$

Lambeck, K., and J. Chappell (2001), Sea level change through the Last Glacial Cycle, Science, 292, 679-686.

Lambeck, K., C. Smither, and P. Johnston (1998), Sea-level change, glacial rebound and mantle viscosity for northern Europe, Geophys. J. Int., 134, $102-144$

Landvik, J. Y., S. Bondevik, A. Elverhoi, W. Fjeldskaar, J. Mangerud, O. Salvigsen, M. J. Siegert, J.-I. Svendsen, and T. O. Vorren (1998), The last glacial maximum of Svalbard and the Barents Sea area: Ice sheet extent and configuration, Quat. Sci. Rev., 17, 43-75.

Legates, D. R., and C. J. Willmott (1990), Mean seasonal and spatial variability in gauge-corrected, global precipitation, Int. J. Climatol., 10, $111-127$.

Le Meur, E., and P. Huybrechts (1996), A comparison of different ways of dealing with isostasy: Examples from modeling the Antarctic ice sheet during the last glacial cycle, Ann. Glaciol., 23, 309-317.

Licciardi, J. M., P. U. Clark, J. W. Jenson, and D. R. Macayeal (1998), Deglaciation of a soft-bedded Laurentide ice sheet, Quat. Sci. Rev., 17, $427-448$.

Mangerud, J., T. Dokken, D. Hebbeln, B. Heggen, Ó. Ingólfsson, J. Y. Landvik, V. Mejdahl, J. I. Svendsen, and T. O. Vorren (1998), Fluctuations of the Svalbard-Barents Sea ice sheet during the last 150,000 years, Quat. Sci. Rev., 17, 11-42.

Mangerud, J., J. I. Svendsen, and V. I. Astakhov (1999), Age and extent of the Barents and Kara ice sheets in Northern Russia, Boreas, 28, $46-80$.

Mangerud, J., V. Astakhov, and J.-I. Svendsen (2002), The extent of the Barents-Kara ice sheet during the Last Glacial Maximum, Quat. Sci. Rev., $21,111-119$

Marshall, S. J., and G. K. C. Clarke (1999), Modeling North American freshwater runoff through the Last Glacial Cycle, Quat. Res., 52, 300315

Marshall, S. J., and P. U. Clark (2002), Basal temperature evolution of North American ice sheets and implications for the 100-kyr cycle, Geophys. Res. Lett., 29(24), 2214, doi:10.1029/2002GL015192.

Marshall, S. J., L. Tarasov, G. K. C. Clarke, and W. R. Peltier (2000), Glaciological reconstructions of the Laurentide Ice Sheet: Physical processes and modeling challenges, Can. J. Earth Sci., 37, 769-793. 
Marshall, S. J., T. S. James, and G. K. C. Clarke (2002), North American Ice Sheet reconstructions at the Last Glacial Maximum, Quat. Sci. Rev. 21, 175-192.

McManus, J. F., D. Oppo, L. D. Keigwin, J. L. Cullen, and G. C. Bond (2002), Thermohaline circulation and prolonged interglacial warmth in the North Atlantic, Quat. Res., 58, 17-21.

Meissner, K. J., A. J. Weaver, H. D. Matthews, and P. M. Cox (2003), The role of land surface dynamics in glacial inception: A study with the UVic Earth System Model, Clim. Dyn., 21, 515-537.

Milne, G. A., J. L. Davis, J. X. Mitrovica, H.-G. Scherneck, J. M. Johansson, M. Vermeer, and H. Koivula (2001), Space-geodetic constraints on glacial isostatic adjustment in Fennoscandia, Science, 291, $2381-2385$.

Milne, G. A., J. X. Mitrovica, and D. P. Schrag (2002), Estimating past continental ice volume from sea-level data, Quat. Sci. Rev., 21, 361376

Oerlemans, J., and C. J. van der Veen (1984), Ice Sheets and Climate, Springer, New York.

Pagiatakis, S. D., and P. Salib (2003), Historical relative gravity observations and the time rate of change of gravity due to postglacial rebound and other tectonic movements in Canada, J. Geophys. Res., 108(B9), 2406, doi:10.1029/2001JB001676.

Peltier, W. R. (1994), Ice Age paleotopography, Science, 265, 195-201.

Peltier, W. R. (2002), On eustatic sea level history: Last Glacial Maximum to Holocene, Ouat. Sci. Rev., 21, 377-396.

Peltier, W. R. (2004), Global glacial isostasy and the surface of the ice-age earth: The ICE-5G (VM2) Model and GRACE, Ann. Rev. Earth Planet Sci., 32, 111-149.

Peltier, W. R., D. L. Goldsby, D. L. Kohlstedt, and L. Tarasov (2000), Iceage ice-sheet rheology: Constraints from the Last Glacial Maximum form of the Laurentide ice sheet, Ann. Glaciol., 30, 163-176.

Pfeffer, W. T., M. B. Dyurgerov, M. Kaplan, J. Dwyer, C. Sassolas, A. E. Jennings, B. Raup, and W. Manley (1997), Numerical modeling of late Glacial Laurentide advance of ice across Hudson Strait: Insights into terrestrial and marine geology, mass balance, and calving flux, Paleoceanography, 12(1), 97-110.

Pollack, H. N., S. J. Hurter, and J. R. Johnson (1993), Heat flow from the Earth's interior: Analysis of the global data set, Rev. Geophys., 31(3), $267-280$.

Pollard, D., et al. (2000), Comparisons of ice-sheet surface mass budgets from Paleoclimate Modeling Intercomparison Project (PMIP) simulations, Global Planet. Change, 24, 79-106.

Polyak, L., S. L. Forman, F. A. Herlihy, G. Ivanov, and P. Krinitsky (1997), Late Weichselian deglacial history of the Svyataya (Saint) Anna Trough, northern Kara Sea, Arctic Russia, Mar. Geol., 143, 169-188.

Polyak, L., M. H. Edwards, B. J. Coakley, and M. Jakobsson (2001), Ice shelves in the Pleistocene Arctic Ocean inferred from glaciogenic deepsea bedforms, Nature, 410, 453-457.

Ritz, C., A. Fabre, and A. Letréguilly (1997), Sensitivity of a Greenland ice sheet model to ice flow and ablation parameters: Consequences for the evolution through the last glacial cycle, Clim. Dyn., 13, 11-24.

Ritz, C., V. Rommelaere, and C. Dumas (2001), Modeling the evolution of Antarctic ice sheet over the last 420,000 years: Implications for altitude changes in the Vostok region, J. Geophys. Res., 106(D23), $31,943-31,964$

Rolandone, F., J.-C. Mareschal, and C. Jaupart (2003), Temperatures at the base of the Laurentide ice sheet inferred from borehole temperature data, Geophys. Res. Lett., 30(18), 1944, doi:10.1029/2003GL018046.
Sclater, J. G., C. Jaupart, and D. Galson (1980), The heat flow through oceanic and continental crust and the heat loss of the Earth, Rev. Geophys., 18(1), 269-311.

Shackleton, N. J. (1987), Oxygen isotopes, ice volume and sea level, Quat. Sci. Rev., 6, 183-190.

Siegert, M. J., J. A. Dowdeswell, M. Hald, and J. I. Svendsen (2001), Modeling the Eurasian Ice Sheet through a full (Weichselian) glacial cycle, Global Planet. Change, 31, 367-385.

Stouffer, R. J., and S. Manabe (1999), Response of a coupled ocean-atmosphere model to increasing atmospheric carbon dioxide: Sensitivity to the rate of increase, J. Clim., 12, 2224-2237.

Stuiver, M., P. J. Reimer, E. Bard, J. W. Beck, G. S. Burr, K. A. Hughen, B. Kromer, F. G. McCormac, J. v. d. Plicht, and M. Spurk (1998), INTCAL98 Radiocarbon Age Calibration, Radiocarbon, 40, $1041-$ 1083.

Svendsen, J. I., et al. (1999), Maximum extent of the Eurasian ice sheets in the Barents and Kara Sea region during the Weichselian, Boreas, 28, $234-242$.

Svendsen, J. I., et al. (2004a), Late Quaternary ice sheet history of northern Eurasia, Quat. Sci. Rev., 23(11), 1229-1272, doi:10.1016/j.quatscirev. 2003.12.008.

Svendsen, J. I., V. Gataullin, J. Mangerud, and L. Polyak (2004b), The glacial history of the Barents and Kara Sea region, in Quaternary Glaciations - Extent and Chronology, edited by J. Ehlers and P. Gibbard, pp. 1-10, Elsevier, New York.

Tarasov, L., and W. R. Peltier (1999), Impact of thermo-mechanical ice sheet coupling on a model of the $100 \mathrm{kyr}$ ice-age cycle, J. Geophys. Res., 104(D8), 9517-9545.

Tarasov, L., and W. R. Peltier (2000), Laurentide ice sheet aspect ratio in models based on Glen's flow law, Ann. Glaciol., 30, 177-186.

Tarasov, L., and W. R. Peltier (2004), A geophysically constrained large ensemble analysis of the deglacial history of the North American icesheet complex, Quat. Sci. Rev., 23, 359-388.

Vieli, A., M. Funk, and H. Blatter (2001), Flow dynamics of tidewater glaciers: A numerical modeling approach, J. Glaciol., 47(159), 595-606.

Waelbroeck, C., L. Labeyrie, E. Michel, J. C. Duplessy, J. F. McManus, K. Lambeck, E. Balbon, and M. Labracherie (2002), Sea-level and deep water temperature changes derived from benthic foraminifera isotopic records, Ouat. Sci. Rev., 21, 295-305.

Weaver, A. J., M. Eby, A. F. Fanning, and E. C. Wiebe (1998), Simulated influence of carbon dioxide, orbital forcing and ice sheets on the climate of the Last Glacial Maximum, Nature, 394, 847-853.

Weertman, J. (1964), The theory of glacier sliding, J. Glaciol., 5(39), $287-$ 303 .

Winograd, I. J. (2001), The magnitude and proximate cause of ice-sheet growth since 35,000 yr B.P., Quat. Res., 56, 299-307.

Yokoyama, Y., K. Lambeck, P. De Deckker, P. Johnston, and L. K. Fifield (2000), Timing of the last glacial maximum from observed sea-level minima, Nature, 406, 713-716.

Zweck, C., and P. Huybrechts (2003), Modeling the marine extent of northern hemisphere ice sheets during the last glacial cycle, Ann. Glaciol., 37, $173-180$.

P. Huybrechts and C. Zweck, Alfred-Wegener-Institut für Polar - und Meeresforschung, Postfach 120161, D-27515 Bremerhaven, Germany. (czweck@awi-bremerhaven.de) 